$-$

ARGONNE NATIONAL LABORATORY

P. O. Box 299

Lemont, Illinois
ANL-5372

Metallurgy and Ceramics

(TID-4500, 14th Ed.)

AEC Research and

Development Report

RECORDING QUARTZ DIFFERENTIAL DILATOMETER

by

L. T. Lloyd

Metallurgy Division

Partial Report - Metallurgy Program 4.1.6

July 1959

The information covered in this report has not appeared in any of the Metallurgy Quarterly Reports

Operated by The University of Chicago under

Contract W-31-109-eng-38 


\section{DISCLAIMER}

This report was prepared as an account of work sponsored by an agency of the United States Government. Neither the United States Government nor any agency Thereof, nor any of their employees, makes any warranty, express or implied, or assumes any legal liability or responsibility for the accuracy, completeness, or usefulness of any information, apparatus, product, or process disclosed, or represents that its use would not infringe privately owned rights. Reference herein to any specific commercial product, process, or service by trade name, trademark, manufacturer, or otherwise does not necessarily constitute or imply its endorsement, recommendation, or favoring by the United States Government or any agency thereof. The views and opinions of authors expressed herein do not necessarily state or reflect those of the United States Government or any agency thereof. 


\section{DISCLAIMER}

Portions of this document may be illegible in electronic image products. Images are produced from the best available original document. 
TABLE OF CONTENTS

Page

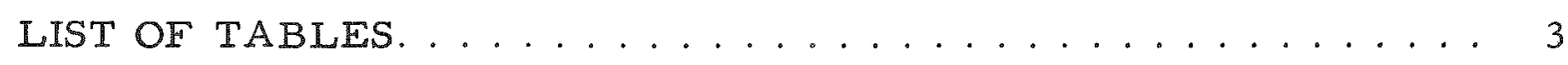

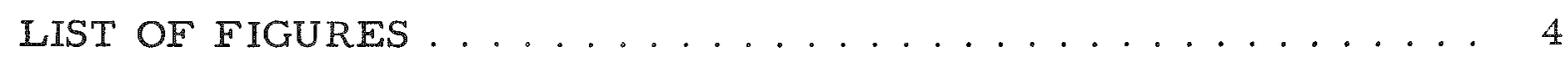

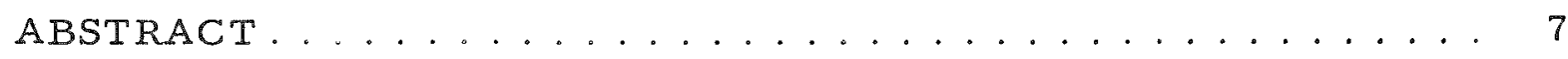

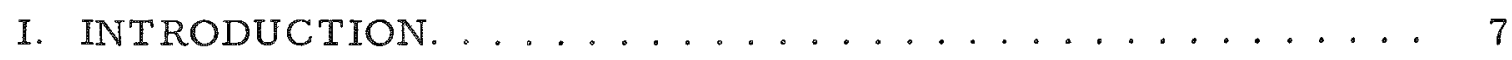

II. SELECTION OF INSTRUMENT TYPE ............ 7

III. DILATOMETER EQUIPMENT. .................... 8

A. Expansion Recorder....................... 8

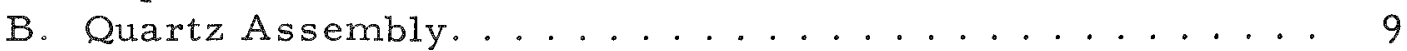

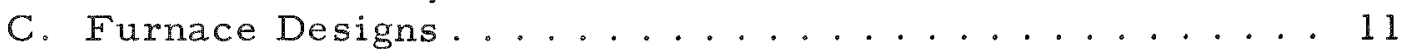

D. Furnace Control Instrumentation ............ 12

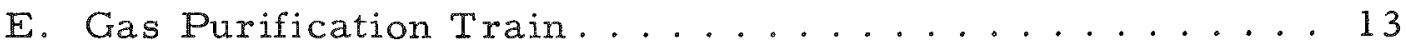

IV. DILATOMETER CALIBRATION ............... . 13

A. Mechanical Magnification Factors ............ 13

B. Correction for Expansion of Quartz Assembly ...... 15

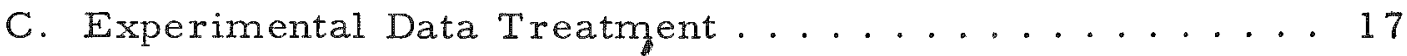

D. Accuracy of Measurements................ 18

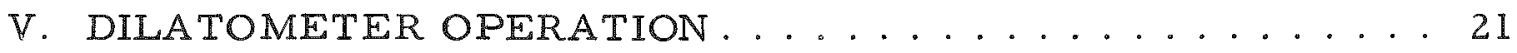

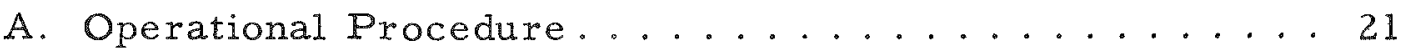

B. Typical Experimental Curves ............ 23

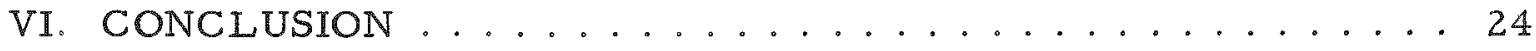

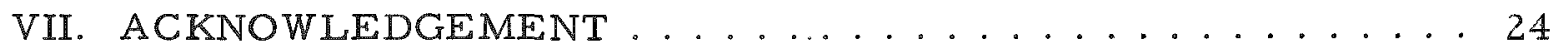

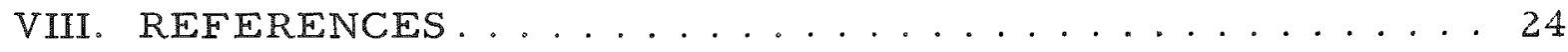




\section{LIST OF TABLES}

No.

Title

Page

I. Magnifications Obtained with Gear Combinations of the

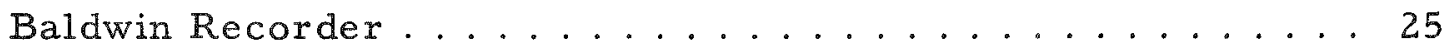

II. Illustration of Experimental Data Treatment Method . . . . . 25

III. Experimental Expansion Data for Specimen DQ. . . . . . . 26

IV. Experimental Expansion Data for Pure Silver. . . . . . . . 27

V. Reproducibility and Accuracy of the Dilatometer........ 28

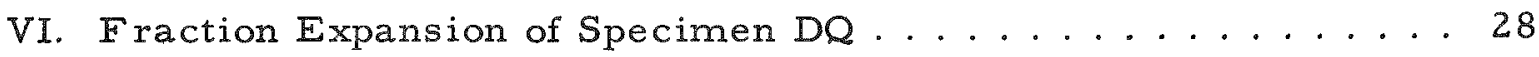

VII. Fraction Expansion of Pure Silver ............... 29 


\section{LIST OF FIGURES}

No.

Title

Page

1. Thermal Expansion Recorder................. 30

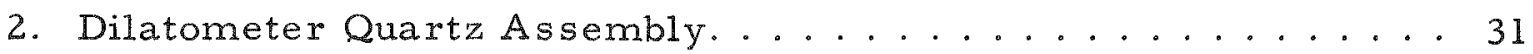

3. Invar Clamp and Lever Arm between Upper Push Rod and Linear Variable Differential Transformer Core......... 32

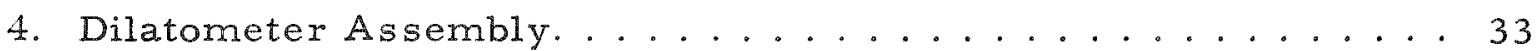

5. Low-mass Furnace for Fast Heating and Cooling Rates...... 34

6. Temperature Gradients of Fast Heating and Cooling Rate

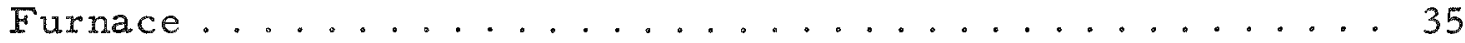

7. Slower Heating and Cooling Rate Furnace.......... 36

8. Recorder and Control Instrument Console of the Dilatometer... 37

9. Over-all View of Quartz Differential Dilatometer and

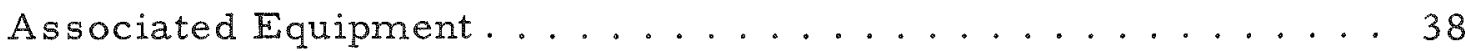

10. Schematic Sketch of Mechanical Linkages in the Baldwin Recorder..................... 39

11. Schematic Representation of Correction Applied for Expansion of Quartz Assembly Components . . . . . . . . . . . . . 40

12. Fraction Expansions of Specimens DQ and Pure Silver..... 41

13. Schematic Diagram of Air System for Recording Quartz Differential Dilatometer ............... 42

14. Schematic Wiring Diagram for Gas Purification Train of Recording Quartz Differential Dilatometer .......... 43

15. Schematic Power Wiring Diagram for Recorder and Control Instruments of Recording Quartz Differential Dilatometer. . . . 44

16. Schematic Thermocouple Wiring Diagram for Recorder and Control Instruments of Recording Quartz Differential

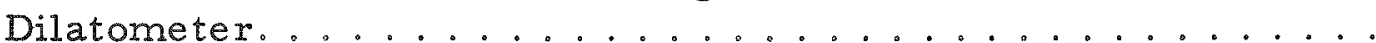




\section{LIST OF FIGURES}

No. Title

17. Thermal Expansion Curves for $300^{\circ} \mathrm{C}$ Rolled and 2-hour, $575^{\circ} \mathrm{C}$ Annealed Uranium Rod Sample Tested in a Direction Parallel to the Rolling Direction. Sample was cycled between

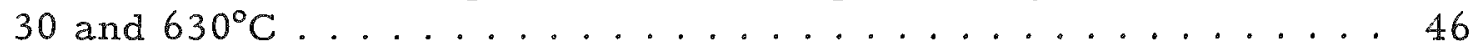

18. Thermal Expansion Curves for $300^{\circ} \mathrm{C}$ Rolled and $575^{\circ} \mathrm{C}$ Annealed Uranium Rod Samples Tested Parallel to the Rolling Direction. a. Normal behavior of contraction upon cooling in the alpha phase. b. Abnormal expansion upon cooling in the alpha phase. . 47

19. Expansion of an Alpha-Uranium Single Crystal in a Direction Near the $[010] \ldots \ldots \ldots \ldots$ 
•

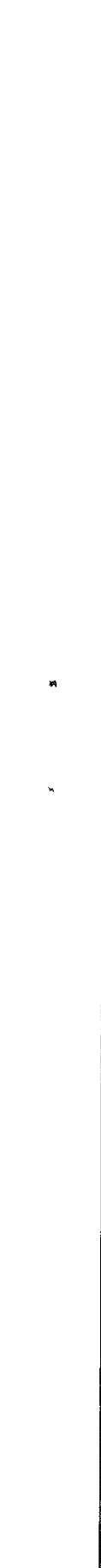

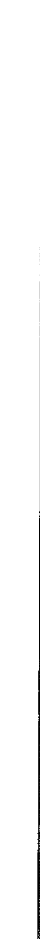




\title{
RECORDING QUARTZ DIFFERENTIAL DILATOMETER
}

\author{
L. T. Lloyd
}

\begin{abstract}
The design of a recording quartz differential dilatometer is described. The instrument embodies desirable features of automatic operation with a flexible heating and cooling program control plus continuous recording of expansion data, as well as other features unique to the problem of dilatation measurement at hand. Sensitivity, precision and accuracy of the instrument are discussed in relation to data obtained with standard specimens. Operational procedures and typical experimental curves are included.
\end{abstract}

\section{INTRODUCTION}

Metallurgical investigations often require a means of measuring thermal expansion with reasonable accuracy. Commercially available dilatometers do not incorporate all of the features desired for such an apparatus at Argonne National Laboratory. Thus, it was necessary to design and construct a piece of equipment to fulfill the needs at hand.

\section{SELECTION OF INSTRUMENT TYPE}

The choice of the particular type of instrument was dependent upon several factors; some of these are given below:

1. good precision with sensitivity of at least $1 \times 10^{-5}$ inch;

2. capability to accommodate specimens from 0.1 to 1 inch in length:

3. operating conditions:

(a) sample protected by an inert atmosphere;

(b) maximum temperature of $1000^{\circ} \mathrm{C}$;

(c) rapid heating and cooling rates, as well as slower rates:

(d) completely automatic:

1) continuous recording of temperature versus expansion as a $\mathrm{X}-\mathrm{Y}$ plot;

2) continuous heating and cooling program control; 
(e) flexible temperature program control;

(f) small load on the sample;

(g) long-term stability of the equipment.

In general, dilatometers are designed with one, or combinations, of three basic measurement methods: mechanical, optical and electrical. Each system has its advantages as well as disadvantages; rather detailed discussions of these have been given by Wyman. (1) Equipment constructed on the basis of purely mechanical principles is quite rugged and necessarily creates large "dead loads" on a specimen. Such systems involve multiple lever arms and/or gear trains which are difficult, but not impossible, to construct without "backlash." Dilatometers with optical systems are complicated and difficult to construct and maintain. The primary objections to electrical systems are their somewhat delicate nature and instability over long periods of time; however, the latter objection can be overcome if a null-type instrumentation is used.

The measurement method finally selected for the present dilatometer is similar to that reported by Rosenholtz and Smith. (2) The system involves the desirable featuxes of rugged construction and good accuracy associated with a well-built mechanical system, but minimizes the "dead load" on the specimen by insertion of an intermediate null-type electrical transducer.

\section{DILATOMETER EQUIPMENT}

A. Expansion Recorder

One of the most reliable transducers for converting linear motion into an electrical signal is the linear variable differential transformer ( $L V D T$ ), and its output signal can be recorded in many ways. An application of this transducer is the measurement of strain during tensile testing, and instruments designed for this purpose are commercially available. A Baldwin Stress-Strain recorder was selected as the "nucleus" of the present dilatometer.

The IVDT used in conjunction with a Baldwin recorder consists of three coils of wire wound coaxially on a ceramic spool. The central coil is the primary and the two outer coils are secondaries connected so that their outputs are in opposition. A magnetic core can be moved axially in the hole through the spool. The primary is energized from a step-down transformer and induces voltages in the two secondaries via magnetic lines of flux. The position of the magnetic core controls the magnitudes of induced voltages. Because two secondaxies are connected in opposition, only the net signal is transmitted to the recorder, where it is electronically amplified, and the resultant signal enexgizes a syncro motor. 
As the recorder drum is rotated by the gear train between it and the syncro motor, the core of a second LVDT within the instrument is repositioned by a screw also driven by the gears. The internal LVDT has its primary coil connected in series with that of the external LVDT, and the net output of the secondaries of the internal LVDT is connected in opposition to that of the external LVDT. Thus, when the external core is moved, a signal is transmitted to the recorder, it is amplified and causes the motor to rotate the recorder drum and reposition the internal core so as to result in a zero net output from the secondaries of the two LVDT's. This is a null-type circuitry; consequently, the recorder is independent of line-voltage variations and is stable for long periods of time.

The electrical circuitry of the recorder, per se, does not magnify the motion imparted to the external LVDT core; rather it acts as a means of transferring the information from one point to another. The magnifications are controlled by the sizes of the gears in the recorder. These will be discussed in detail in the section dealing with instrument calibration. The outstanding feature of this system is that the dilatation specimen is unaware of the large forces required to move the gear train.

Recorder drum rotation constitutes the $Y$ ordinate of the $X-Y$ plot of temperature versus expansion. The abscissa, $X$, is furnished by mechanically connecting the pen of the Baldwin recorder to the pen drive mechanism of a Brown Electronic temperature recorder. The temperature indicated by the latter instrument is sensed by a $\mathrm{Pt} / \mathrm{Pt}-10 \% \mathrm{Rh}$ thermocouple located at the dilatation specimen. The arrangement of the two instruments is shown in Figure 1. A spring-driven "window shade" roller is attached to the Baldwin recorder so that a continuous $\mathrm{X}-\mathrm{Y}$ plot can be obtained with an ordinate greater than the circumference of the recorder drum.

B. Quartz Assembly

Once a suitable means of recording the motion resulting from thermal expansion of a specimen is established, it is necessary to provide a method of transmitting this motion to the sensing equipment. The fused quartz assembly shown schematically in Figure 2 is used in the present dilatometer The upper end of the outer quartz tube is cemented into an Invar sleeve. At the opposite end a lower quartz push rod is cemented concentrically with the aid of a brass bushing. A short, cylindrical quartz sleeve, whose internal surface is ground and polished to give a smooth, circular cross section and into which the dilatation specimen is inserted, fits over a ground and polished plug fused to the upper end of the lower push rod. A similar ground and polished plug is fused to the lower end of the upper push rod; it also fits into the short cylindrical tube Fused to the opposite end of the upper push rod is a ground and polished plug which rides on the "bearing" surface of the Invar sleeve. 
The upper push rod contacts the other components of the quartzassembly only in two places; the contact area at the Invar sleeve is essentially a point and the one at the short cylindrical tube, a line. In this manner, frictional forces opposing motion between the quartz assembly components are reduced. The specimen support tube is designed to accommodate samples 0.200 inch in diameter and 1 inch in length; shorter specimens can be used by making up the total 1 inch length with suitable quartz "shims." The over-all length of the quartz assembly is approximately 36 inches and the center of the dilatation specimen is located at approximately 24 inches from the free end of the Invar sleeve.

For operation, the quartz assembly is inserted into a furnace and the Invar sleeve is placed into an Invar clamp, shown in Figure 3 , so that the center of the sample is at the furnace center. The clamp also supports an Invar lever arm which magnifies the motion of the external LVDT core with respect to the motion of the upper push rod. Invar is used for all of these components to reduce errors arising from small variations in room temperature. The lever arm is supported on two pivots of 1/16 inch diameter hardened steel balls which mate with "V"-shaped grooves in hardened steel studs affixed to the lever arm; these surfaces are held together by a small spring. The rounded end of the adjustable screw in contact with the polished plug fused to the upper push rod constitutes one end of the lever. The other end is a. conical, slightly rounded point in contact with the non-magnetic support fot the LVDT core. The fixture at the right of Figure 3 applied a light spring load to the core support so that it will follow the motion of the upper push rod when the specimen is contracting as well as when it is expanding.

A view of the dilatometer assembly is shown in Figure 4 . The inert gas atmosphere and specimen thermocouple are introduced into the assembly at the lower end by means of a flexible rubber tube. The gas enters the system via one arm of a glass " $T$ " and the thermocouple is inserted through the " $\mathrm{T}$. Holes are drilled in the wall of the lower push rod to allow circulation of the gas throughout the assembly. Additional holes are drilled in the Invar sleeve to permit the gas to leave the system freely and to prevent high flow velocities in the small annulus between the Invar sleeve "bearing" and the polished quartz plug on the upper end of the upper push rod. The entire assembly is inclined at about 8 degrees to insure positive contact between the upper push rod and the specimen. The measured total load applied in a direction parallel to the axis of the specimen is only 80 grams.

As shown in Figure 4, the dilatometer assembly is suspended by coil springs attached to standards mounted on a table, and the table is set on foam rubber pads. The combination of the foam rubber pads and the coil springs reduced the transmission of building vibrations to the dilatometer. 
C. Furnace Designs

Two different furnace designs are used to supply heat to the dilatation samples. The choice of the particular furnace for a given test is dependent upon the desired heating and cooling rates. One of the requirements for the dilatometer was capability of fast heating and cooling rates. For this purpose, a furnace with low mass and external water cooling coils was developed. The second furnace, for more normal dilatometric measurements, has a greater mass and is not force cooled.

The low-mass furnace design found suitable is shown schematically in Figure 5. It consists of a 12 inch long, $1 / 2$ inch inside diameter, $3 / 4$ inch outside diameter, porous Alundum tube wound with 0.025 inch diameter Pt-10\% Rh resistor wire capable of carrying 25 amperes at 110 volts. The wire is wound with uniform spacing over the central 6 inch length and taper wound for 2 inches at each end. This heating element, coated with Alundum cement, is centrally located by means of Transite support rings in a 12 inch long steel shell of 2 inch outside diameter and $1 / 32$ inch wall thickness. The annulus between the shell and the heating element is filled with silica sand. Copper coils are soldered to the central 7 inches of the shell and are continually cooled with water. Provision is made for control of furnace temperature by means of a $\mathrm{Pt} / \mathrm{Pt}-10 \% \mathrm{Rh}$ thermocouple located at the center of the furnace winding.

With this furnace it is possible to heat a sample from room temperature to $1000^{\circ} \mathrm{C}$ in approximately 15 minutes; cooling back to room temperature requires approximately 30 minutes. A series of temperature gradients along the furnace length, taken at constant power input, is shown in Figure 6. The central 2 to 3 inches shows fairly uniform temperatures but they are not satisfactory for accurate dilatometric measurements. This behavior, of course, is associated with the low mass and forced cooling.

The furnace of greater mass for more accurate dilatometric measurements at slower heating and cooling rates is shown schematically in Figure 7. Pt-10\% Rh resistor wire is wound on a $1 \frac{1}{2}$ inch outside diameter furnace tube machined from Lavite. Grooves for the wire are machined as a double thread with 4 double threads per inch over the central 10 inch length of the total 12 inches. In this manner, the furnace can be wound noninductively to prevent induced currents in the thermocouple wires. The inside of the furnace tube has a $1 / 2$ inch diameter, 4 inch long hole at one end and is bored at the other end to receive a 4 inch long, 1 inch outside diameter and $1 / 2$ inch inside diameter nickel "heat sink" plus a. similar Lavite sleeve. A slot for the furnace control the rmocouple is machined parallel to the tube axis and on the 1 inch inside diameter. The thermocouple bead is placed near the center of the furnace and directly in line with a hole drilled to one of the wire grooves. Thus, the 
thermocouple bead directly "sees" part of the furnace resistor wire and, therefore, gives sensitive temperature control. Transite supports at each end locate the tube assembly in the center of a 4 inch outside diameter, $1 / 16$ inch thick and 12 inch long steel shell; the annulus is filled with insulating material. Temperature along the central $3 \frac{1}{2}$ inches of this furnace are very constant.

The above furnace is the one shown mounted on the dilatometer assembly in Figure 4. The two furnaces can be easily interchanged on the cradle support. Since both have $\mathrm{Pt}-10 \% \mathrm{Rh}$ windings, the maximum useful temperature of the dilatometer is not dictated by the furnaces but rather by the fused quartz assembly, since it cannot be used for extended periods of time at temperatures of $1000^{\circ} \mathrm{C}$ or above because of its tendency to transform to $\beta$ cristobalite.

\section{Furnace Control Instrumentation}

Power to the dilatometer furnace is provided by an autotransformer whose voltage is controlled by a Conoflow air-operated diaphragm motor. Air pressure to this motor is determined by pneumatic controls.

Filtered, constant-pressure air is supplied to a pneumatic timepattern transmitter and a potentiometer controller. Output air pressure of the time-pattern transmitter, as determined by the position of a cam follower arm, is fed to the controller. The position of the arm as a function of time is determined by the shape of a plastic cam and the speed at which it rotates. Cams can be cut in any shape and interchangeable gear trains can be used to obtain one rotation of a cam in $1,4,6,12$ and 24 hours. By these means, temperature programs can be selected with time durations as short as $1 / 2$ hour and as long as 24 hours.

The air pressure from the time-pattern transmitter continually positions the set point of the potentiometer controller connected to the furnace control thermocouple. As additional power is needed to bring the furnace temperature to that of the set point the controller supplies additwonal air pressure to the Conoflow motor and it drives the autotransformer to increase the power to the furnace. As an additional control refinement. a Brown Strip Chart Interval Controller, operating from the differential between the furnace and specimen thermocouples, can be used to stop and start the cam drive motor of the preumatic time-pattern transmitter.

Figure 8 shows the recorder and control instrument console of the dilatometer. The Brown Electronic Strip Chart and Baldwin recorders of the X-Y plotter are shown at the top. The Brown Pneumatic Time-Pattern Transmitter is at the right, the Brown Potentiometer Controller is in the center and the Brown Strip Chart Interval Controller is at the left. 
E. Gas Purification Train

The final dilatometer component is the purification train employed to treat welding-grade argon gas for the inert atmosphere in the quartz assembly. It consists of the following components:

1. Drierite (anhydrous calcium sulphate) for removal of gross moisture content,

2. copper oxide needles at $450^{\circ} \mathrm{C}$ for oxidation of hydrocarbons,

3. Drierite for water removal,

4. Ascarite for carbon dioxide removal,

5. copper turnings at $450^{\circ} \mathrm{C}$ for removal of the major portion of the oxygen,

6. uranium chips at $700^{\circ} \mathrm{C}$ for removal of residual oxygen and the nitrogen content of the gas,

7. and phosphorus pentoxide for removal of residual water.

This purification system has given quite satisfactory results even when testing uranium samples to temperatures of 800 to $900^{\circ} \mathrm{C}$ over periods of time as long as 100 hours.

Figure 9 shows the over-all arrangement of the dilatometer and its associated equipment. The entire assembly is located in a room whe re temperature and humidity are controlled.

\section{DILATOMETER CALIBRATION}

Before a dilatometer can become a useful research tool it must be calibrated so that observed expansion quantities may be converted to their true values. Calibrations are normally obtained by testing materials of known expansion and determining by comparison the applied corrections. In this case, however, the apparatus can be calibrated by considering the mechanical magnification factors and the thermal expansion of fused quartz.

\section{A Mechanical Magnification Factors}

Although the important feature of the dilatometer is the use of linear variable differential transformers to reduce the "dead load" on a specimen and to transmit the motion of the upper push rod to the expansion recorder, the LVDT's do not enter into consideration of the expansion magnifications. 
The two things that control magnifications are the gear train in the Baldwin recorder and the lever arm between the upper push rod and the external LVDT core.

The magnification factor of the lever was determined by measuring the lengths of its two arms. The distance between the pivot points and the center of the adjustable push rod follower is $0.763 \pm 0.002$ inches and the distance between the pivot points and the conical point which bears against the external LVDT core mounting is $4.170 \pm 0.002$ inches. The magnification factor of the lever arm is then $4.170 / 0.763=5.465$.

Specifications for the Baldwin recorder state a sensitivity of positioning the internal LVDT core with respect to the external one of $\pm 1 \times 10^{-5}$ inches in a ratio of 1 to 1 . A 0.001 inch displacement of the upper push rod is then magnified to 0.005465 inch displacement of the LVDT core in the recorder At the same time that the internal LVDT core is being displaced by the syncro motor, a set of gears is causing rotation of the recordex drum. By considering the ratio of these two motions the magnification factors can be determined for the Baldwin recorder.

It is important to point out that there is no detectable backlash in the gear train: this conclusion is based upon the following tests. The external LVDT core was kept in a fixed position and the location of the pen on the recorder chart was noted. By turning off the power to the motor and rotating the gear at the left of the recorder drum (Figure 1), the internal LVDT core and the recorder drum were displaced from their equilibrium positions. When the windings of the motor were again energized the drum rotated so that the pen returned to its original position. The same behavior was noted when the recorder drum and internal LVDT core were displaced in the opposite direction, and the same results were obtained for all recorder magnifications These tests also indicate that the amplifier cir cuitry faitkfullv positions the internal LVDT core as dictated by the position of the external L TDT core.

Magnification factors of the Baldwin recorder can be determined with the ard of the schematic sketch of Figure 10. Twro sets of gears can be changed; these are $A-B$ and $C-D$. The various gear combinations and scale designations are tabulated in Table I together with the magnitudes of motion of the upper push rod that are indicated by one-inch travel on the expansion plot. The latter values were obtained as illustrated below for the $\mathrm{H}^{\prime}$ scale.

For each 0.001 inch motion of the external LVDT core the internal core is moved 0.001 inch. Since the drive screw for the internal core has 50 threads per inch, it advances 0.020 inch per revolution or 0.001 inch in $1 / 20$ of a revolution. One-twentieth revolution of the screw is accompanied by a rotation of the recorder drum equal to $(1 / 20)\left(\frac{48}{26} \times \frac{96}{48} \times \frac{40}{58} \times \frac{54}{19 \dot{6}}\right)=$ 0.038462 revolution, where the numbers in parentheses are the numbers of 
teeth on the gears. $\frac{A}{B} \times \frac{C}{D} \times \frac{E}{F} \times \frac{F}{G}$, respectively. Since the recorder drum is 3.875 inches in diameter, it has a circumference of $\pi \times 3.875=$ 12.1737 inches, and 0038462 revolution corresponds to $0.038462 \times 12.1737=$ 0.468225 inchtravel on the drum surface or the same quantity on the expansion chart. From the magnification factor of the lever arm, 0.001 inch travel of the upper push rod results in 0.005465 inch travel of the external LVDT core. Thus 0.001 inch travel of the upper push rod results in $(0.005465 / 0.001)=0.468225=2.558850$ inch travel on the expansion plot. From this, the motion of the upper push rod indicated by a movement of one inch on the expansion plot is $0.001 / 2.558850=3.91 \times 10^{-4}$ inches.

Calculated magnitudes of motion of the upper push rod were checked by inserting shims $0.00151,0.00299$ and $0.00509 \pm 0.00001$ inch thick between the upper push rod and the lever arm follower. The average displacements on the expansion plot for twelve measurements with each shim and using the $\mathrm{H}^{8}$ scale were 3.86, 7.66 and 13.02 inches, respectively. These data give values for motion of the upper push rod as indicated by one inch on the expansion plot of $3.91 \mathrm{z} \times 10^{-4}, 3.90_{3} \times 10^{-4}$ and $3.909 \times 10^{-4}$ inches, respectively. These agree quite well with the calculated value of $3.91 \times 10^{-4}$ inches and they serve to demonstrate its validity.

B. Correction for Expansion of Quartz Assembly

Once the magnifications of the upper push rod motion obtained by the lever arm and the Baldwin recorder are known, the remaining unknown is the relationship between this motion and the expansion of the specimen. Since this is a differential dilatometer, the magnitude of the upper push rod motion is not exactly the same as the expansion of the sample, but it is the expansion of the specimen minus the expansion of quartz. The basic assumption made is that the expansion of the outer quartz tube due to temperature changes is compensated by the expansion of the quartz push rods where the components exist concentrically. Then at a given temperature the quartz whose expansion must be considered has a length equal to that of the test specimen.

To a first approximation the measured expansion of an unknown sample can be corrected by adding the expansion of a length of quartz equal to the original length of the sample. This correction, however, does not take into consideration the fact that the length of the sample changes with temperature and thus the length of the quartz that must be considered is also changed, because its expansion, in general, is not the same as that of the sample

The situation that exists in the dilatometer is depicted schematically in Figure 11. Figure lla shows a general cross-sectional view of the quartz assembly in the vicinity of the test specimen. Because of the assumption 
that the expansion of the outer tube is compensated by a like expansion of the quartz push rods where the components exist concentrically, the only portion of the assembly whose dimensional changes need be considered is that between sections $A$ and $B$. The quartz sleeve acts merely as a specimen support and does not enter into the consideration because it is confined at one end only. Thus, the two things to be considered are the outer quartz tube over the length of the specimen and the specimen itself. These can be considered as fixed in the same plane at section $A$, as shown in Figure $1 \mathrm{lb}$. At the reference temperature the test specimen length $\left(\mathrm{L}_{0}(\mathrm{~S})\right)$ equals the length of the quartz $\left(L_{0}(\Omega)\right)$. As shown in Figure $11 \mathrm{c}$, upon heating to a temperature the test specimen expands by $\Delta L_{(S)}$ to a length $L(S)$. Also, the original length of quartz expands by $\Delta L(Q)$ to a length $L(Q)$. In general $L(\Omega)$ is different than $L(S)$. The observed expansion of the test specimen is $\Delta L\left(S_{t}\right)$. This is not equal to $\Delta L(S)-\Delta L(Q)$ but rather to $\Delta L(S)-\Delta L\left(Q_{t}\right)$, where $\Delta L\left(Q_{t}\right)$ is the quartz expansion obtained upon heating to temperature $t$ the length of quartz $L_{0}\left(Q_{t}\right)$, whose expanded length at $\mathrm{t}$ is $\mathrm{L}\left(\mathrm{Q}_{\mathrm{t}}\right)$. Thus, some means must be arrived at which will permit correction of the measured expansion data for $\Delta L\left(\Omega_{t}\right)$ and not $\Delta L(Q)$. A simple procedure for accomplishing this correction can be arrived at according to the following argument.

From Figure $11 \mathrm{c}$ it is obvious that:

$$
L_{(S)}=L_{0}(S)+\Delta L\left(S_{t}\right)+\Delta L\left(Q_{t}\right)
$$

Also, at temperature $t$,

$$
L_{(S)}=L_{\left(\Omega_{t}\right)}
$$

and

$$
\mathrm{L}_{\left(\mathrm{Q}_{\mathrm{t}}\right)}=\mathrm{L}_{0}\left(\mathrm{\Omega}_{\mathrm{t}}\right)+\Delta \mathrm{L}_{\left(\mathrm{Q}_{\mathrm{t}}\right)}
$$

type:

The expansion of quartz can be expressed by an equation of the

$$
L_{\left(Q_{t}\right)}=L_{0}\left(Q_{t}\right)\left(1+\alpha t+\beta t^{2}\right)=L_{0}\left(Q_{t}\right) \lambda_{Q},
$$

where $L_{\left(\Omega_{t}\right)}$ equals the length at $t^{\circ} \mathrm{C}$ and $L_{0}\left(Q_{t}\right)$ is the length at a reference temperature.

Substituting equation (2) into equations (3) and (4):

$$
L_{(S)}=L_{0}\left(\Omega_{t}\right)+\Delta L\left(Q_{t}\right)
$$


and

$$
L_{(S)}=L_{0}\left(Q_{t}\right) \lambda_{Q},
$$

or

$$
\mathrm{L}_{0}\left(\mathrm{Q}_{\mathrm{t}}\right)=\mathrm{L}_{(\mathrm{S})} / \lambda_{\mathrm{Q}}
$$

Substituting equation (6) into equation (5),

$$
L_{(S)}=\frac{L_{(S)}}{\lambda_{Q}}+\Delta L_{\left(Q_{t}\right)}
$$

or

$$
\Delta L_{\left(Q_{t}\right)}=L_{(S)}-\frac{L_{(S)}}{\lambda_{Q}}
$$

Substituting equation (7) into equation (1),

$$
L(S)=L_{0}(S)+\Delta L\left(S_{t}\right)+L(S)-\frac{L(S)}{\lambda_{Q}}
$$

or

$$
L_{(S)} / \lambda_{Q}=L_{0(S)}+\Delta L_{\left(S_{t}\right)}
$$

or

$$
\left.L_{(S)}=\lambda_{Q}\left[L_{0}(S)+\Delta L_{(S}\right)\right]
$$

Thus, the true length of an unknown sample at temperature $t$ is the original length plus the measured expansion multiplied by the $\lambda_{\mathrm{Q}}$ for quartz based upon a value of one at the reference temperature. The reference temperature is defined as the temperature at which the original length of the test sample was measured.

C. Treatment of Experimental Data

Once the mechanical magnification factors and the method of correcting for quartz expansion are established, the plot of experimental temperature versus expansion can be converted into true expansion data in the following manner. The measured expansion values at desired temperature intervals are read from the experimental curve in units of $1 / 3$ inch to the nearest 0.05 part thereof and tabulated, as shown in Table II; the data presented are the average of five measurements with the $H^{\prime}$ scale of the dilatometer for a specimen $D Q$ furnished by the Bureau of Standards. The values are then multiplied by the magnification factor for the scale and added to the original 
length of the sample to yield the indicated length at temperature $t^{\circ} \mathrm{C}$ $\left[L_{0}(S)+\Delta L\left(S_{t}\right)\right]$. These are then multiplied by the appropriate $\lambda_{Q}$ as determined from an equation expressing the length of fused quartz at temperature $t$ as a function of its length at $0^{\circ} \mathrm{C}$ and temperature as follows:

$$
L_{Q_{t}{ }^{\circ} \mathrm{C}}=L_{Q_{0}{ }^{\circ} \mathrm{C}}\left(1+0.6006 \times 10^{-6} t-0.1148 \times 10^{-9} t^{2}\right) .
$$

This equation was fitted by least mean square analys is to the mean expansion coefficient data reported by Souder and Hidnert. (3) In the present example, $\lambda_{Q}$ at $t$ is based upon a value of 1 at $25^{\circ}$ at which the original length of the sample was measured. The experimental data in this form represent the true length, $L_{(S)}$, of the sample at $t$. It is convenient to convert the data to represent fraction expansion $\left(f_{E}\right)$ in the following manner:

$$
f_{E}=\left[L(S) t^{\circ} \mathrm{C}-\mathrm{L}(\mathrm{S}) 25^{\circ} \mathrm{C} / \mathrm{L}(\mathrm{S}) 25^{\circ} \mathrm{C}\right] \text {. }
$$

Expressions of the data in this form permit comparison with information from other sources. Table II also contains fraction expansion data for specimen $D Q$ as calculated from the equation fitted by least mean square analysis to the mean thermal expansion data given by Hidnert. (4) This equation is

$$
L_{t}{ }^{\circ} \mathrm{C}=L_{0}{ }^{\circ} \mathrm{C}\left(1+16.46 \times 10^{-6} t-0.425 \times 10^{-9} t^{2}+2.36 \times 10^{-12} t^{3}\right) .
$$

The two sets of fraction expansion data for specimen DQ are given graphically in Figure 12 .

\section{Accuracy of Measurements}

Numerous sources of errors must be considered when attempting to evaluate individual contributions to the inaccuracy of the dilatometer; among these are:

1. original length of the sample,

2. uniformity of temperature in the sample,

3. differential in temperature between the sample and the outer quartz tube,

4. differential in temperature between the outer quartz tube and the quartz push rods,

5. calibration of the lever arm magnification,

6. calibration of the Baldwin recorder magnifications, 
7. calibration of the specimen temperature the rmocouple,

8. ability to read the experimental data from the $\mathrm{X}-\mathrm{Y}$ recorder plot,

and many others. The errors associated with several of these are extremely difficult, if not impossible, to evaluate. The only reasonable approach is to reduce the effects of the factors where possible and to determine the over-all accuracy with experimental data. In the final analysis, the measures of accuracy are: (1) the ability of the instrument to reproduce data and (2) the agreement between experimental and known expansion data.

To this end, numerous dilatation tests have been performed on a specimen of pure silver and the DQ sample furnished by the Bureau of Standards. The experimental data for three scales of the Baldwin recorder ( $L^{\prime}, I^{\prime}$ and $H^{\prime}$ ) are given in Tables III and IV. Each specimen was tested five times for each dilatometer scale at heating and cooling rates of approximately $2^{\circ} \mathrm{C}$ per minute. The maximum temperature of $750^{\circ} \mathrm{C}$ was selected to eliminate potential errors from deterioration of the fused quartz when heated to high temperatures for long periods of time.

As a measure of reproducibility, or precision, standard deviations $(\sigma)$ from the average measured expansions at temperature $t$ have been determined for each specimen and each magnification scale according to the following equation:

$$
\sigma=1.2533 \frac{\sum_{i=1}^{N}\left|R_{i}\right|}{N},
$$

where $R_{i}$ is the difference between the average expansion at temperature $t$ and the i'th individual observation. The quantity $N$ is the number of observations and is equal to $5 \times 29=145$ for each group of data. The standard deviations are tabulated in Table $\mathrm{V}$ in terms of upper push rod motion.

To obtain a measure of the accuracy of the dilatometer, the average expansions at temperature $t$ for the two specimens and the three magnification scales were converted to fraction expansions according to the method of data treatment given above and compared to values calculated from previously reported data. These values are tabulated in Tables VI and VII. The source of information for specimen DQ has been cited previously(4) and the expansion of pure silver, as reported by Esser and Eusterbrook,(5) is represented by the equation:

$$
\mathrm{L}_{t}{ }^{\circ} \mathrm{C}=\mathrm{L}_{0}{ }^{\circ} \mathrm{C}\left(1+19.49 \times 10^{-6} \mathrm{t}+1.04 \times 10^{-9} t^{2}+2.38 \times 10^{-12} \mathrm{t}^{3}\right)
$$


Probable errors for the data are given in Table $V$. These were calculated according to the following relationship:

$$
\text { P.E. }=0.8453 \frac{\sum_{i=1}^{N}\left|R_{i}\right|}{N}
$$

where $R_{i}$ is the difference between the $i$ 'th observed and calculated fraction expansions at temperature $t$ and $N$ is the number of observations. Figure 12 shows a plot of the fraction expansions determined with the $H^{\prime}$ scale of the dilatometer in comparison to the values from previously reported information.

The sensitivities of the dilatometer, as indicated by the magnitudes of expansion represented by a 0.05 portion of the $1 / 3$ inch units read from the experimental curves, are $\pm 0.26 \times 10^{4}, \pm 0.13 \times 10^{-4}$ and $\pm 0.06 \times 10^{-4}$ inches for the $L^{\prime}, I^{\prime}$ and $H^{\prime}$ scales of the Baldwin recorder, respectively. The standard deviations given in Table $V$ show that the precision of the dilatometer is essentially unaffected by the Baldwin recorder scale and has a value of approximately $\pm 0.5 \times 10^{-4}$ inches. Obviously, this is greater than the sensitivities and, therefore, should not show an appreciable variation with the different recorder scales. Apparently variations in thermal conditions of the quartz assembly and the sample from test to test are significant, even though every effort was made to reduce these factors. The accuracy of the dilatometer, as indicated by the probable error values derived from comparisons of measured and reported expansions (Table V), is approximately $1 \times 10^{-4}$ inches and also is essentially unaffected, at least not systematically. by the recorder scale employed. An error of $1 \times 10^{-4}$ inches in measured expansions at low temperatures represents a considerable percentage; however, this percentage becomes smaller at higher temperatures for normal materials which may expand as much as 0.015 to 0.020 inches for an original 1 inch length. The errors in mean expansion coefficients derived from expansion data obtained with the dilatometer, of course, are smaller and would be on the order of $0.2 \times 10^{-6}$ per ${ }^{\circ} \mathrm{C}$ for larger temperature intervals.

The plots in Figure 12 show that the curve of measured expansion for specimen $D Q$ falls below the curve from reported data. On the other hand, the measured curve for pure silver falls below the reported expansion at low temperatures and crosses over to a position above the reported expansion curve at higher temperatures. Since the deviations of measured from reported expansions are not consistent, the data can not be used to apply a correction to measured expansions of other samples. It is impossible to delineate the source of these inconsistencies. They may be due to variations in data obtained. with the dilatometer, to variations in the specimens as compared to those used for determining the previously reported data, or even to inaccuracies of the data. 


\section{DILATOMETER OPERATION}

Figures 13, 14, 15 and 16 record the schematic diagrams of the air and electrical systems employed in the present dilatometer. The figures are self-explanatory and are useful for the following description of the dilatometer operation

\section{A. Operational Procedure}

After a dilatation sample has been prepared for testing by suitable cleaning and its length measured at a known temperature, it is placed in the fused quartz assembly. For this purpose, the upper push rod and the specimen sleeve are removed through the opening in the Invar sleeve. The specimen sleeve is placed over the plug at the lower end of the upper push rod and the specimen is placed inside the sleeve. The push rod, sleeve and specimen are then replaced in the quartz assembly and positioned so that the specimen sleeve fits around the plug on the upper end of the lower push rod. The ends of the specimen should be in contact with the faces of the plugs on the upper and lower push rods.

The front of the furnace is tilted upward and the lower end of the quartz assembly is inserted into the furnace tube. The furnace is rotated back to its normal position and the Invar sleeve is clamped in the Invar head. Particular care must be taken in this operation to prevent breaking the quartz assembly.

The flexuble rubber tube is placed over the lower end of the outer quartz tube. The specimen thermocouple is inserted through this rubber tube, through the inside of the lower push rod and through the hole in the specimen support plug so that the bead is adjacent to the sample or inside a small hole in the sample, as the case may be The clamp at the lower end of the rubber tube is then tightened to prevent escape of the purified gas at that point and to hold the thermocouple in position. Upon placing ice in the thermocouple cold-junction vacuum bottle, the dilatometer is readv for operation

A flow of purfied argon gas is furnished to the quartz assembly by adjusting the pressure regulator at the tank so that a differential in height of $1 / 2$ inch is shown on the manometer. After the gas train has been purged, the heating elements are energized by turning on the main power switch (Figure 14). Approximately one-half hour is required for the furnaces to come to temperature: the temperatures are controlled by power input via the autotransformers. An Inter-Matic tmmer in the circuit can be used to turn the power on at any convenient time, as well as to turn it off if the dilatation test is ended after normal working hours 
The heating and cooling program is established by selecting a suitably shaped cam and the proper cam drive gear train and placing these into the Brown Pneumatic Time-Pattern Transmitter. Air is supplied to the pneumatic instruments by opening the inlet valve. The various gauge pressures indicated in Figure 13 are then checked and regulator adjustments are made where necessary. The recorder and control instruments are then energized by turning on the appropriate switches, as shown in Figure 15.

Once the recorder and control instruments have warmed up, the proper seating of the dilatation specimen is checked by, firstly, adjusting the position of the external LVDT core mount so that the expansion of the sample will not cause the core to go beyond positions corresponding to the limits of \pm 0.060 inch from the null position and, secondly, by lightly tapping the quartz assembly so that the Baldwin recorder drum rotates to a minimum position. The position of the Baldwin recorder pen with respect to the pen of the Brown strip chart recorder which operates from the specimen thermocouple is checked and adjusted if necessary.

The test is started by turning on the motor switch of the Brown Pneumatic Time-Pattern Transmitter. If control by the differential in temperature between the furnace and specimen is used, the control point of the Brown Strip Chart Interval Controller is set to the desired position and the cam drive motor will be stopped and started via the relay shown in Figure 15. The polarity of the thermocouple differential emf can be reversed by the multipoint switch shown in Figure 16. An Electrovane switch in the Brown Pneumatic Time-Pattern Transmitter automatically reverses the differential emf polarity upon going from the heating to cooling, or vice versa, parts of the cycle. If differential control is not used, the set point of the Brown Strip Chart Interval Controller is placed all the way upscale and the heating and cooling program is controlled by the Brown Pneumatic Time-Pattern Transmitter only.

The dilatometex operates automatically at all times and can be run through as many cycles as desired. It can be stopped at any predetermined time by setting the Inter-Matic timer connected to the Brown Pneumatic Time-Pattern Transmitter.. When the timer switch opens, the power to the cam drive motor is shut off; however, the power to the other instruments and the dilatometer furnace remains on. For this reason, it is desirable to stop the cam in a position where the power being furnished to the dilatometer furnace is as near a minimum as possible, so that the test specimen is not subjected to elevated temperatures for prolonged periods of time. The operation of the dilatometer is terminated, firstly, by turning off the switches which furnish electrical power to the control instruments, dilatometer furnace and gas train furnaces and, secondly, by closing the argon gas and air valves. 


\section{B. Typical Experimental Curves}

Some typical experimental expansion curves obtained with the Recording Quartz Differential Dilatometer for uranium samples are shown in Figures 17, 18 and 19. The curves of Figures 17 and 18 have been retraced from the actual experimental curves so as to remove the fine line network of the paper used in the Baldwin recorder. The experimental curve of Figure $18 \mathrm{a}$ was 31 inches long and that for Figure $18 \mathrm{~b}, 18$ inches long. The units of the abscissa for each plot are millivolts measured from the Pt/Pt-10\% Rh specimen thermocouple, and the ordinate units are indicated expansions for the particular scale of the Baldwin recorder.

Figure 17 shows a series of curves obtained by cycling a $300^{\circ} \mathrm{C}$ rolled and 2 -hour, $575^{\circ} \mathrm{C}$ annealed uranium sample between 30 and $630^{\circ} \mathrm{C}$. The $H$ scale of the Baldwin recorder was used and the sample was tested parallel to its rolling direction. Heating time for each cycle was 19 minutes and cooling time was 42 minutes. Progressive growth upon cycling is typical of highly orientated polycrystalline alpha-uranium.

Figure 18 illustrates the behavior of $300^{\circ} \mathrm{C}$ rolled and $575^{\circ} \mathrm{C}$ annealed samples when heated through the $\alpha=\beta$ and $\beta=\gamma$ transformations. These curves are from a dilatometric study of transformation temperatures of uranium.(6) The samples were measured parallel to the rolling direction with the I' scale of the Baldwin recorder. They were heated rapidly to $600^{\circ} \mathrm{C}$ and further heated at a rate of $1^{\circ} \mathrm{C} /$ minute; after reaching the maximum temperature in the gamma phase, the specimens were cooled at a rate of $1^{\circ} \mathrm{C} /$ minute back through the $\beta \rightarrow \alpha$ transformation and then rapidly cooled to room temperature at a rate somewhat slower than that of heating in the alpha phase. Figure 18a. illustrates the normal change in expansion characteristics within the alpha phase as a result of passing through the phase transformations. Figure $18 \mathrm{~b}$ illustrates an anomalous behavior in that upon cooling in the alpha phase the sample expanded rather than contracted.

Figure 19 is a photograph of the actual experimental curve obtained for an alpha-uxanium single crystal tested in a direction near the [010]. The thermal expansion of this and other alpha-uranium single crystals axe presented in more detail in another report. (7) The length of the crystal at $21^{\circ} \mathrm{C}$ was 0.1415 inch. The curve was obtained with the $H^{\prime}$ scale of the Baldwin recorder with the sample heated and cooled at a rate of approximately $5^{\circ} \mathrm{C} /$ minute. Because the sample expanded upon cooling, the curve shown in Figure 19 is the one obtained during the cooling portion of the cycle. This curve physically demonstrates the contraction of alpha-uranium in the [010] direction upon heating. 


\section{CONCLUSION}

The design and operational characteristics of a recording quartz differential dilatometer have been described. Although the precision and accuracy of the instrument are not as good as those of other dilatometers, for example, an interferometer-type instrument, the equipment embodies desirable features of heating and cooling program flexibility plus completely automatic operation.

\section{ACKNOWLEDGEMENT}

The development of this dilatometer was carried out under the direction of F. G. Foote and H. H. Chiswik. Much of the instrumentation was selected by S. H. Paine. The initial design and construction of the apparatus was supervised and performed by W. M. Lehrer. The author's contributions to the design and operational features of the instrument were primarily of a minor nature and aimed at minimizing inaccuracies and inconsistencies. The assistance of $\mathrm{J}$. L. Walker in performing many of the dilatometric tests is gratefully acknowledged. Finally, the author is indebted to P. Hidnert of the National Bureau of Standards who so kindly furnished the DQ standard specimen.

\section{REFERENCES}

1. Wyman, L. L., "Precision Equipment for Metallurgical Analysis," KAPL-663 (January 1952).

Wyman, L. L., "Improved Precision Equipment for Metallurgical Analysis," KAPL-654 (November 15, 1951).

2. Rosenholtz, J. L. and Smith, D. T., "Linear Thermal Expansion of Calcite, Var. Iceland Spar and Yule Marble," American Mineralogist (1949) $33,846-854$.

3. Souder, W. and Hidnert, P., "Measurements of the Thermal Expansion of Fused Quartz," Scientific Papers of the Bureau of Standards, 21 (1925).

4. Hidnert, P., National Bureau of Standards. Private communication.

5. Esser, H. and Eusterbrook, H., "Untersuchung der Wärmeausdehnung von einigen Metallen und Legierungen mit einen Verbesserten Dilatometer," Archiv Für Das Eisenhüttenwesen (1941) 14, 341-345.

6. Blumenthal, B., Baumrucker, J.E. and Lloyd, L. T., "The Transformation Temperatures of High Purity Uranium," ANL-5957.

7. Lloyd, L. T., "Thermal Expansion of Alpha-Uranium Single Crystals," ANL-5972. 
Magnifications Obtained with Gear Combinations of the Baldwin Recorder

\begin{tabular}{|c|c|c|c|c|c|}
\hline \multirow{2}{*}{$\begin{array}{c}\text { Scale } \\
\text { Designation }\end{array}$} & \multicolumn{4}{|c|}{ Number of Teeth on Gears* } & \multirow{2}{*}{$\begin{array}{l}\text { Motion of Upper Push Rod } \\
\text { Indicated by } 1 \text { in. on Expansion } \\
\text { Plot } \times 10^{4} \text { (inches) }\end{array}$} \\
\hline & A & $\mathrm{B}$ & C & $\mathrm{D}$ & \\
\hline I & 42 & 32 & 18 & $a_{6}$ & 21.98 \\
\hline $\mathrm{I}$ & 42 & 32 & 72 & 72 & 1099 \\
\hline $\mathrm{H}$ & 42 & 32 & 96 & 48 & 5.50 \\
\hline $\mathrm{UH}$ & $\$ 2$ & 32 & 120 & 24 & 2.20 \\
\hline $\mathrm{L}^{\prime}$ & 48 & 26 & 48 & 96 & 15.63 \\
\hline$T^{\prime}$ & 48 & 26 & 72 & 72 & 7.81 \\
\hline$H^{\prime}$ & 48 & 26 & 96 & 18 & 3.91 \\
\hline $\mathrm{UH}^{\prime}$ & 48 & 26 & 120 & 24 & 1.56 \\
\hline
\end{tabular}

* Gears E, F, and G (Figure 10) are not changed in the Baldwin Recorder. They have 40,54 and 192 teeth, respectively.

TABLE II

Illustration of Experimental Data Treatment Method (Specumen DQ, LO(S) $=1.0003$ in. at $25^{\circ} \mathrm{C}$ )*

\begin{tabular}{|c|c|c|c|c|c|c|}
\hline \multirow{2}{*}{$\begin{array}{l}\text { Temparature } \\
\left(t^{\circ} \mathrm{C}\right)\end{array}$} & \multirow{2}{*}{$\Delta L_{\left(S_{t}\right)}$} & \multirow{2}{*}{$\mathrm{LO}_{(\mathrm{S})}+\Delta \mathrm{L}_{\left(\mathrm{S}_{\mathrm{l}}\right)}$} & \multirow{2}{*}{$\lambda Q$} & \multirow{2}{*}{$\mathrm{L}(\mathrm{s})$} & Fraction Expansion $x 10^{4}$ & $\left(\frac{\mathrm{L}_{\mathrm{t}^{\circ} \mathrm{C}}-\mathrm{L}_{25^{\circ} \mathrm{C}}}{\mathrm{L}_{25^{\circ} \mathrm{C}}}\right.$ \\
\hline & & & & & Experimental & Calculated** \\
\hline 25 & 0.00 & 1.000300 & 1.000000 & 1.000300 & 0.00 & 0.00 \\
\hline 50 & 2.58 & 1.000636 & 1.000015 & 1.000651 & 3.51 & 4.11 \\
\hline 75 & 5.29 & 1.000989 & 1.000029 & 1.001018 & 7.18 & 8.21 \\
\hline 100 & 8.16 & 1.001363 & 1.000044 & 1.001 .407 & 11.07 & 12.32 \\
\hline 125 & 10.96 & 1.001728 & 1.000058 & 1.001780 & 14.86 & 16.44 \\
\hline 150 & 13.94 & 1.002116 & 1.000072 & 1.002188 & 18.89 & 20.55 \\
\hline 175 & 16.95 & 1.002508 & $1.00008 i$ & 1.002590 & 22.95 & 24.68 \\
\hline 200 & 20.07 & 1.002915 & 1.000100 & 1.003015 & 2714 & 28.81 \\
\hline 225 & 23.20 & 1.003323 & 1.000114 & 1.003437 & 3136 & 32.96 \\
\hline 250 & 26.37 & 1.003736 & 1.000128 & 1.003804 & 35.03 & 37.12 \\
\hline 275 & 29.47 & 1.004140 & $1.0001+2$ & 1.004282 & 39.81 & 41.30 \\
\hline 300 & 32.63 & 1.004552 & 1.000155 & 1004707 & 44.06 & 4550 \\
\hline 325 & 35.76 & 1004960 & $1.00010 \%$ & 1.005128 & 28.27 & 49.72 \\
\hline 350 & 38.93 & 1005372 & 1.000181 & 1.005540 & 52.53 & 5497 \\
\hline 375 & 4222 & 1005801 & 1.000194 & 1005900 & 50.95 & 58.24 \\
\hline 400 & 1549 & 1006227 & 1.000207 & 1000430 & 01.34 & 02.53 \\
\hline 425 & 4881 & 1006060 & 1000220 & 1.040831 & $05.7^{9}$ & 60.86 \\
\hline 450 & 52.09 & 1.007087 & 1000232 & 1007321 & 70.19 & 71.22 \\
\hline 475 & 55.48 & 1.007529 & 1.000211 & 1.007775 & $7-\frac{1}{2} .73$ & 75.61 \\
\hline 500 & 58.67 & 1007945 & 1.000257 & 1.008204 & 3901 & 80.04 \\
\hline 525 & 62.04 & 1.008384 & $1.00020 y$ & 1008655 & 33.52 & 84.51 \\
\hline 550 & 65.48 & 1.008832 & 1.000281 & 1.009110 & 88.13 & 8902 \\
\hline 575 & 68.82 & 1. 009267 & 1000292 & 3.009562 & 92.59 & 93.58 \\
\hline 600 & 71.92 & 1.009671 & 1.000304 & 1.009978 & 90.75 & 18.17 \\
\hline 625 & 75.21 & 1010100 & 1.000310 & 1.010419 & 101.10 & 102.82 \\
\hline 650 & 78.67 & 1010551 & $1.000: 25$ & 1.010881 & 105.78 & 1137.02 \\
\hline 675 & 82.14 & 1.011 .003 & 1.000338 & 1.011344 & 110.41 & 11227 \\
\hline 700 & 85.69 & 1.011465 & $1.0003 .4 \%$ & $101181 \%$ & 11515 & 117.07 \\
\hline 725 & 89.20 & 1.011923 & 1.000360 & 1.012257 & 114.83 & $1 \therefore 1.93$ \\
\hline 750 & 92.80 & 1.012392 & 1.000371 & $1.01270 \%$ & $12 \frac{1}{2} .0 \frac{1}{2}$ & 120.85 \\
\hline
\end{tabular}

* Meaning of symbols are as follows:

$\Delta \mathrm{L}_{\left(\mathrm{S}_{\mathrm{t}}\right)}=$ Observed expansion of test sample in units of $1 / 3 \mathrm{in}$. read from experimental curve. Values given are average of 5 measurements made with $\mathrm{H}^{\prime}$ scale of Baltwin Recorder. $\begin{aligned} \mathrm{L}_{\mathrm{O}}(\mathrm{S}) & +\Delta \mathrm{L}_{\left(\mathrm{S}_{\mathrm{t}}\right)}= \\ & =\text { indicated length of test sample at } 1^{\circ} \mathrm{C}-\text { length at } 25^{\circ} \mathrm{C} \text { plus } \Delta \mathrm{L}_{\left(\mathrm{S}_{\mathrm{t}}\right) \mathrm{read} \text { from }} \\ & \text { experimental curre time-scale magaification factor of } 1.303 \times 0^{-4} \text {. }\end{aligned}$

$\lambda_{Q}=$ Quartz correction factor calculated from equation $\mathrm{L}_{Q_{\mathrm{t}}{ }^{\circ} \mathrm{C}}=\mathrm{L}_{Q_{0}{ }^{\circ} \mathrm{C}}\left(1+0.6006 \times 10^{-6} \mathrm{t}-\right.$

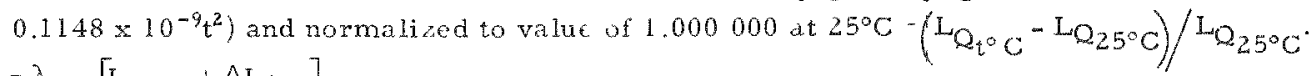
$L_{(S)}=\lambda_{Q}\left[L_{O}(S)+\Delta L_{\left(S_{t}\right)}\right]$.

**Fraction expansion as calculated from equation fitted to mean expasision coefficient data for specimen $D Q$ given by Hidnert. (4) 
TABLE II I

Experimental Expansion Data for Specimen DQ*

\begin{tabular}{|c|c|c|c|c|c|c|c|c|c|c|c|c|c|c|c|c|c|c|}
\hline \multirow{2}{*}{$\begin{array}{l}\text { Temperature } \\
\qquad\left(t^{\circ} \mathrm{C}\right)\end{array}$} & \multicolumn{6}{|c|}{ Baldwin Recorder L' Scale } & \multicolumn{6}{|c|}{ Baldwin Recorder I' Scale } & \multicolumn{6}{|c|}{ Baldwin Recorder H' Scale } \\
\hline & 济 1 & $\$ 2$ & $\$ 3$ & : 4 & \$\$ 5 & Average & *6 & 涪 7 & H8 & 济9 & 10 & Average & 11 & 12 & $\# 13$ & \#14 & 15 & Average \\
\hline 25 & 0.00 & 0.00 & 0.00 & 0.00 & 0.00 & 0.00 & 0.00 & 0.00 & 0.00 & 0.00 & 0.00 & 0.00 & 0.00 & 0.00 & 0.00 & 0.00 & 0.00 & 0.00 \\
\hline 50 & 065 & 0.65 & 0.50 & 0.60 & 0.60 & 0.60 & 1.20 & 1.35 & 1.25 & 1.4 .0 & 1.25 & 1.29 & 2.80 & 2.60 & 2.40 & 2.25 & 2.85 & 2.58 \\
\hline 75 & 1.35 & 1.30 & 1.25 & 1.30 & 1.30 & 1.30 & 2.55 & 2.70 & 2.60 & 2.75 & 2.60 & 2.64 & 5.50 & 5.40 & 5.10 & 4.95 & 5.50 & 5.29 \\
\hline 100 & 2.10 & 2.00 & 2.00 & 1.95 & 2.00 & 2.01 & 3.95 & 4.15 & 4.05 & 4.20 & 4.10 & 4.09 & 8.20 & 8.30 & 7.90 & 8.15 & 8.25 & 8.16 \\
\hline 125 & 280 & 2.70 & 2.65 & 2.65 & 2.75 & 2.71 & 5.35 & 5.60 & 5.40 & 5.65 & 5.45 & 5.49 & 11.05 & 11.20 & 10.80 & 10.50 & 11.25 & 10.96 \\
\hline 150 & 3.50 & 3.45 & 3.40 & 3.45 & 3.45 & 3.45 & 6.80 & 7.00 & 6.95 & 7.10 & 6.90 & 6.95 & 14.10 & 14.15 & 13.75 & 13.50 & 14.20 & 13.94 \\
\hline 175 & 4.20 & 4.15 & 4.15 & 4. 20 & 4.25 & 4. 19 & 8.30 & 8.55 & 8.40 & 8.75 & 8.4 .5 & 8.49 & 17.05 & 17.10 & 16.75 & 16.65 & 17.20 & 16.95 \\
\hline 200 & 4.95 & 4.95 & $4 ., 95$ & 5.00 & 5.05 & 4.98 & 9.90 & 10.10 & 10.05 & 10.35 & 10.00 & 10.08 & 20.15 & 20.35 & 19.75 & 19.75 & 20.35 & 20.07 \\
\hline 225 & 5.65 & 5.80 & 5.75 & 5.85 & 5.85 & 5.78 & 11.45 & 11.60 & 11.65 & 12.00 & 11.60 & 11.66 & 23.25 & 23.45 & 22.85 & 23.00 & 23.45 & 23.20 \\
\hline 250 & 6.40 & 6.55 & 6.55 & 6.60 & 6.60 & 6.54 & 12.95 & 13.25 & 13.20 & 13.60 & 13.20 & 13,24 & 26.30 & 26.70 & 26.05 & 26.30 & 26.50 & 26.37 \\
\hline 275 & 7.15 & 7.40 & 7.25 & 7.40 & 7.45 & 7.33 & 14.60 & 14.75 & 14.80 & 15.10 & 14.80 & 14.81 & 29.35 & 30.00 & 29.00 & 29.30 & 29.70 & 29.47 \\
\hline 300 & 7.95 & 8.10 & 8.05 & 8.20 & 8.25 & 8.11 & 16.10 & 16.45 & 16.35 & 16.60 & 16.30 & 16.36 & 32.50 & 33.15 & 32.35 & 32.50 & 32.65 & 32.63 \\
\hline 325 & 8.70 & 8.90 & 8.80 & 8.90 & 9.00 & 8.84 & 17.65 & 17,95 & 17.90 & 18.15 & 17.90 & 17.91 & 35.60 & 36.30 & 35.10 & 35.95 & 35.85 & 35.76 \\
\hline 350 & 9.50 & 9.70 & 9.65 & 9.70 & 9.80 & 9.67 & 19.25 & 19.50 & 19.45 & 19.80 & 19.50 & 19.50 & 38.65 & 39.35 & 38.35 & 39.25 & 39.05 & 38.93 \\
\hline 375 & 10.30 & 10.55 & 10.45 & 10.50 & 10.60 & 10.48 & 20.90 & 21.15 & 21.10 & 21.45 & 21.10 & 21.14 & 41.90 & 42.75 & 41.70 & 42.45 & 42.30 & 42.22 \\
\hline 400 & 11.10 & 11.35 & 11.25 & 11.35 & 11.45 & 11.30 & 22.55 & 22.75 & 22.75 & 23.25 & 22.70 & 22.80 & 45.35 & 46.00 & 44.80 & 45.70 & 45.60 & 45.49 \\
\hline 425 & 11.95 & 12.20 & 12.15 & 12.20 & 12.30 & 12.16 & 24.15 & 24.55 & 24.40 & 24.85 & 24.40 & 24.47 & 48.65 & 49.30 & 48.15 & 49.05 & 48.90 & 48.81 \\
\hline 450 & 12.75 & 13.00 & 13.00 & 13.05 & 13.10 & 12.98 & 25.85 & 26.25 & 26.05 & 26.45 & 26.05 & 26.13 & 51.95 & 52.60 & 51.45 & 52.25 & 52.20 & 52.09 \\
\hline 4.75 & 13.60 & 13.90 & 13.85 & 13.90 & 13.95 & 13.84 & 27.50 & 27.80 & 27.80 & 28.10 & 27.70 & 27.78 & 55.35 & 56.00 & 54.75 & 55.75 & 55.55 & 55.48 \\
\hline 500 & 14.40 & 14.70 & 14.65 & 14.70 & 14.75 & 14.68 & 29.10 & 29.30 & 29.40 & 29.80 & 29.30 & 29.38 & 58.50 & 59.10 & 58.00 & 59.05 & 58.70 & 58.67 \\
\hline 525 & 15.25 & 15.55 & 15.45 & 15.60 & 15.60 & 15.49 & 30.85 & 31.15 & 31.15 & 31.60 & 31.00 & 31.15 & 61.95 & 62.60 & 61.30 & 62.35 & 62.00 & 62.04 \\
\hline 550 & 16.05 & 16.35 & 16.25 & 16.40 & 16.45 & 16.30 & 32.60 & 32.80 & 32.85 & 33.40 & 32.75 & 32.88 & 65.35 & 66.00 & 64.75 & 65.80 & 65.50 & 65.48 \\
\hline 575 & 16.80 & 17.10 & 17.15 & 17.25 & 17.30 & 17.12 & 34.15 & 34.50 & 34.55 & 34.80 & 34.35 & 34.47 & 68.65 & 69.45 & 68.10 & 69.10 & 68.80 & 68.82 \\
\hline 600 & 17.65 & 17.90 & 17.85 & 17.95 & 18.00 & 17.87 & 35.75 & 36.15 & 35.45 & 36.4 .0 & 35.90 & 35.93 & 71.70 & 72.40 & 71.15 & 72.35 & 72.00 & 71.92 \\
\hline 625 & 18.50 & 18.75 & 18.60 & 18.70 & 18.85 & 18.68 & 37.45 & 37.85 & 37.10 & 38.00 & 37.55 & 37.59 & 75.10 & 75.70 & 74.45 & 75.65 & 75.15 & 75.21 \\
\hline 650 & 19.35 & 19.45 & 19.35 & 19.65 & 19.70 & 19.50 & 39.10 & 39.60 & 38.80 & 39.65 & 39.25 & 39.28 & 78.55 & 79.05 & 77.90 & 79.20 & 78.65 & 78.67 \\
\hline 675 & 20.20 & 20.40 & 20.40 & 20.60 & 20.50 & 20.42 & 40.85 & 41.35 & 40.60 & 41.40 & 41.00 & 41.04 & $81.95^{\prime}$ & 82.50 & 81.35 & 82.80 & 82.10 & 82.14 \\
\hline 700 & 21.05 & 21.35 & 21.30 & 21.40 & 21.35 & 21.29 & 42.60 & 43.10 & 42.35 & 43.10 & 42.75 & 42.78 & 85.50 & 86.20 & 84.85 & 86.30 & 85.60 & 85.69 \\
\hline 725 & 21.90 & 22.25 & 22.15 & 22.20 & 22.20 & 22.14 & 44.35 & 44.80 & 44.10 & 44.95 & 4.4 .55 & 44.55 & 89.10 & 89.55 & 88.35 & 89.80 & 89.20 & 89.20 \\
\hline 750 & 22.85 & 23.15 & 23.05 & 23.15 & 23.10 & 23.06 & 46.15 & 46.65 & 45.85 & 46.75 & 46.35 & 46.35 & 92.60 & 93.15 & 91.95 & 93.50 & 92.80 & 92.80 \\
\hline
\end{tabular}

"Expansion in units of $1 / 3 \mathrm{in}$. read from experimental X-Y plot。 $\mathrm{L}_{\mathrm{O}}(\mathrm{S})=1.0003$ in. at $25^{\circ} \mathrm{C}$. 
TABLE IV

Experamental Expansion Data for Pure Silver*

\begin{tabular}{|c|c|c|c|c|c|c|c|c|c|c|c|c|c|c|c|c|c|c|}
\hline \multirow{2}{*}{$\begin{array}{l}\text { Temperature } \\
\left(t^{\circ} \mathrm{C}\right)\end{array}$} & \multicolumn{6}{|c|}{ Baldwin Recorder L' Scale } & \multicolumn{6}{|c|}{ Baldwin Recorder I' Scale } & \multicolumn{6}{|c|}{ Baldwin Recorder H' Scale } \\
\hline & $M 1$ & 32 & $\mathbb{3}$ & $\$ 4$ & H5 & Average & 76 & $7 ?$ & $\$ 8$ & $\$ 0$ & $\$ 10$ & Average & $\$ 11$ & 壮 & 13 & $\# 14$ & 15 & Average \\
\hline 25 & 0.00 & 0.00 & 0.00 & 0.00 & 0.00 & 0.00 & 0.00 & 0.00 & 0.00 & 0.00 & 0.00 & 0.00 & 0.00 & 0.00 & 0.00 & 0.00 & 0.00 & 0.00 \\
\hline 50 & 0.75 & 0.80 & 0.90 & 0.80 & 0.75 & 0.80 & 1.75 & 1.75 & 1.65 & 1.65 & 1.45 & 1.65 & 3.50 & 3.35 & 3.20 & 3.05 & 3.40 & 3.30 \\
\hline 75 & 1.65 & 1.60 & 1.70 & 1.65 & 1.60 & 1.64 & 3.30 & 3.45 & 3.05 & 3.30 & 3.15 & 3.25 & 6.90 & 6.50 & 6.35 & 6.25 & 6.85 & 6.57 \\
\hline 100 & 2.55 & 2.50 & 2.55 & 2.55 & 2.50 & 2.53 & 5.10 & 4.95 & 5.20 & 5.20 & 4.95 & 5.08 & 10.25 & 10.00 & 10.20 & 9.95 & 10.20 & 10.12 \\
\hline 125 & 3.50 & 3.40 & 3.50 & 3.50 & 3.40 & 3.46 & 0.95 & 6.85 & 7.25 & $=.00$ & 6.75 & 6.96 & 14.15 & 13.85 & 14.00 & 13.30 & 14.00 & 13.86 \\
\hline 150 & 4.40 & 4.30 & 2.25 & 6.40 & 1.35 & 4.34 & 8.70 & 8.75 & 9.15 & 8.85 & 8.70 & 8.83 & 17.70 & 17.45 & 17.80 & 16.35 & 17.40 & 17.34 \\
\hline 175 & 5.30 & 5.25 & 5.20 & 5.35 & 3.301 & 5.28 & $10.6 n$ & 10.55 & 11.15 & 10.80 & 10.55 & 10.73 & 21.65 & 21.10 & 21.60 & 20.70 & 21.35 & 21.28 \\
\hline 200 & 6.30 & 6.20 & 6.15 & $6.30^{1}$ & 6.25 & 6.24 & 12.45 & 12.50 & 12.95 & 12.75 & 12.50 & 12.63 & 25.45 & 24.90 & 25.30 & 24.50 & 25.05 & 25.04 \\
\hline 225 & 7.20 & 7.10 &. .15 & 7.25 & 7.17 & 7.17 & 11.25 & 14.35 & 14.80 & 14.45 & 14.40 & 14.45 & 29.25 & 28.85 & 29.10 & 28.30 & 28.90 & 29.88 \\
\hline 250 & 8.15 & 8.00 & 0.05 & 1.10 & 3.20 & 8.08 & 16.21 & 17.30 & 16.75 & 10.40 & 16.35 & 16.40 & 33.00 & 32.65 & 33.10 & 32.20 & 32.80 & 32.95 \\
\hline 275 & 0.20 & 9.05 & $a_{.} .100$ & 0.101 & 9.10 & a.ro & 18.35 & 12.20 & 18.70 & 10.25 & 18.35 & 18.37 & 36.85 & 36.60 & 36.95 & 36.10 & 36.65 & $3 f .63$ \\
\hline 3014 & 10.15 & 10.00 & 71.00 & 11.17 & 111.11 & $111, n \circ$ & $30.1 n$ & 30.15 & $20 \cdot-5$ & 20.25 & 20.35 & 20.32 & 40.85 & 40.50 & 40.75 & 40.00 & 40.45 & 40.51 \\
\hline 325 & 11.15 & 11.00 & $1.0 n$ & 11.10 & 11.05 & 11.01 & 22.38 & 33.20 & 22.80 & 22.25 & 22.35 & 22.38 & 44.95 & 44.60 & 44.75 & 43.90 & 44.30 & 44.50 \\
\hline 350 & 12.15 & 11.95 & 12.616 & 12.10 & $1 \therefore .11$ & $12.0 r$ & 21.9 & 21.30 & 21.95 & 24.35 & 24.50 & 24.48 & 48.85 & 48.65 & 48.85 & 48.10 & 48.40 & 48.37 \\
\hline 375 & 12.25 & 12.95 & 12.05 & 13.15 & 13.113 & 23.10 & $2 \cdot .3$ & $2+.30$ & 27.00 & $2 r .35$ & 26.45 & 26.49 & 52.85 & 52.65 & 52.80 & 52.00 & 52.30 & 52.52 \\
\hline 400 & 14.20 & 13.95 & 14.03 & 14.20 & 31.13 & 11.11 & $2 \cdot 3^{x}$ & $2 R .40$ & 29.00 & $2 b .35$ & 28.60 & 28.54 & 57.20 & $5 \% .75$ & 56.95 & 56.00 & 56.45 & $56.6^{\circ}$ \\
\hline 125 & 15.20 & 15.00 & 15.10 & 15.25 & $15.2 n$ & 15.15 & $511.5^{2}$ & 0.40 & 31.15 & 30.40 & 30.65 & 30.53 & $61.20^{\circ}$ & 60.80 & 61.10 & 60.15 & 60.35 & 90.72 \\
\hline 450 & 16.25 & 16.05 & $1+.1$ & $1 n .36$ & 11.25 & 16.20 & 32.55 & 32.55 & 33.25 & 32.60 & 32.80 & 32.75 & 65.45 & 63.05 & 65.30 & 4.45 & 64.95 & 65.04 \\
\hline 495 & 17.26 & 17.10 & $1 \% 15$ & 17.35 & $17.2-$ & 17.23 & 31.84 & 34.50 & 35.35 & 34.70 & 34.80 & 34.85 & 69.75 & 69.35 & 6.35 & 68.50 & 60.00 & 69.19 \\
\hline 500 & 18.35 & 18.20 & $1, .25$ & 18.40 & 1.15 & 18.33 & 36.91 & $3+.70$ & 37.35 & 36.85 & 36.95 & 36.99 & 73.90 & 73.65 & -3.65 & 72.75 & 73.20 & 73.43 \\
\hline 525 & 10.45 & 19.25 & 19.35 & 19.70 & $19.5 t$ & 19.41 & 30.10 & 35.95 & 39.70 & 38.90 & 39.29 & 39.17 & 78.30 & 78.05 & 78.10 & 76.90 & 77.65 & 77.90 \\
\hline 550 & 20.50 & .0 .30 & $20 \cdot 10$ & $20 .+5$ & 20.60 & 20.10 & 11.30 & 41.10 & 41.00 & 41.15 & 41.10 & 41.37 & 82.70 & 82.40 & 82.35 & 81.30 & 82.05 & 82.16 \\
\hline $5-5$ & 21.50 & 21.45 & 21.60 & 21.75 & 21.75 & 21.61 & 43.00 & 43.35 & 44.15 & 43.45 & 13.70 & 43.65 & 87.30 & 86.05 & 87.00 & 85.70 & 86.55 & 86.68 \\
\hline 600 & 22.70 & 22.60 & 22.78 & 23.90 & 32.90 & $22 .-6$ & $45.0^{-}$ & 45.65 & $4 f_{.} 3 n$ & 45.75 & 46.00 & 45.95 & 91.80 & 91.50 & 91.45 & 90.20 & 91.00 & 91.19 \\
\hline 625 & -3.90 & 23.75 & $2 ?$ & -1.03 & 31.07 & 23.92 & 48.25 & 1.7 .95 & 19.75 & 48.10 & 48.40 & 48.29 & 96.60 & 96.20 & 95.85 & 94.75 & 95.65 & 95.81 \\
\hline 650 & 25.00 & 24.25 & 27.610 & $2 r .2 n$ & $25 .-5$ & 27.06 & $50 . C 0$ & 50.30 & 51.05 & 50.40 & 50.65 & 50.60 & 101.10 & 100.85 & 100.50 & 99.30 & 100.30 & 100.1 \\
\hline 175 & -+.20 & 26.05 & -8.21 & $-m \cdot 1$ & 2.10 & 27.25 & 53.03 & 52.75 & 53.40 & 52.70 & 52.95 & 52.97 & 105.70 & 105.55 & 104.90 & 101.05 & 105.00 & 105.01 \\
\hline 700 & $2=3$ & -7.35 & $2 \ldots$ & $-\cdots+$ & $27 \cdot 5$ & 37.47 & 55.20 & 55.25 & 55.85 & 55.15 & 55.35 & 55.36 & 110.40 & $|110.20|$ & 109.90 & $1080+5$ & 109.60 & 109.73 \\
\hline 725 & 20.14 & 29.75 & 2. & $\cdots-$ & 29.95 & 20.70 & 58.30 & 59.100 & 52.10 & 57.50 & 57.55 & 57.89 & 115.20 & $115.15 \mid$ & 114.65 & $|113.25|$ & 114.45 & 114.54 \\
\hline 750 & 29.35 & 29.95 & 311.05 & 20.05 & 30.05 & 29.99 & 60.80 & 60.75 & 60.35 & 59.85 & 59.75 & 60.30 & 120.05 & 120.10 & 119.55 & 118.10 & 119.25 & 119.41 \\
\hline
\end{tabular}

*Fxiansicnin units of $1 / 3 \mathrm{in}$. read from experimental $\mathrm{Y}-\mathrm{Y}$ plot. $\mathrm{L}_{\mathrm{O}}(\mathrm{S})=1.0028 \mathrm{an}$. at $25^{\circ} \mathrm{C}$. 
TABLE V

Reproducibility and Accuracy of the Dilatometer

\begin{tabular}{|c|c|c|c|c|}
\hline \multirow{2}{*}{$\begin{array}{c}\text { Baldwin } \\
\text { Recorder } \\
\text { Scale }\end{array}$} & \multicolumn{2}{|c|}{$\begin{array}{c}\text { Standard Deviation of } \\
\text { Observed Expansions from } \\
\text { Average Expansions }\end{array}$} & \multicolumn{2}{|c|}{$\begin{array}{c}\text { Probable Error of } \\
\text { Observed Expansions from } \\
\text { Reported Expansions }\end{array}$} \\
\cline { 2 - 5 } & $\begin{array}{c}\text { Specimen DQ } \\
\times 10^{4} \text { (inches) }\end{array}$ & $\begin{array}{c}\text { Pure Silver } \\
\times 10^{4} \text { (inches) }\end{array}$ & $\begin{array}{c}\text { Specimen DQ } \\
\times 10^{4}\end{array}$ & $\begin{array}{c}\text { Pure Silver } \\
\times 10^{4}\end{array}$ \\
\hline$L^{\prime}$ & 0.532 & 0.493 & 1.500 & 0.848 \\
$I^{\prime}$ & 0.542 & 0.628 & 1.190 & 0.916 \\
$H^{\prime}$ & 0.499 & 0.557 & 1.187 & 0.700 \\
\hline
\end{tabular}

TABLE VI

Fraction Expansion of Specimen DQ

$\left(\frac{L_{t}{ }^{\circ} \mathrm{C}-L_{25^{\circ}} \mathrm{C}}{L_{25^{\circ} \mathrm{C}}}\right)$

\begin{tabular}{|c|c|c|c|c|}
\hline \multirow[t]{2}{*}{$\begin{array}{l}\text { Temperature } \\
\left({ }^{\circ} \mathrm{C}\right)\end{array}$} & \multirow{2}{*}{$\begin{array}{l}\text { Calculated from } \\
\text { Equation* } \\
\times 10^{4}\end{array}$} & \multicolumn{3}{|c|}{$\begin{array}{l}\text { Calculated from Experimental } \\
\text { Measurements } \times 10^{4} \\
\text { (Average of } 5 \text { Determinations) }\end{array}$} \\
\hline & & L'Scale & I' Scale & H' Scale \\
\hline 25 & 0.00 & 0.00 & 0.00 & 0.00 \\
\hline 50 & 4.11 & 3.28 & 3.51 & 3.51 \\
\hline 75 & 8.21 & 7.06 & 7.16 & 7.18 \\
\hline 100 & 12.32 & 10.91 & 11.08 & 11.07 \\
\hline 125 & 16.44 & 14.70 & 14.87 & 14.86 \\
\hline 150 & 20.55 & 18.69 & 18.81 & 18.89 \\
\hline 175 & 24.68 & 22.70 & 22.96 & 2.2 .95 \\
\hline 200 & 28.81 & 26.94 & 27.23 & 27.14 \\
\hline 225 & 32.96 & 31.25 & 31.48 & 31.36 \\
\hline 250 & 37.12 & 35.35 & 35.74 & 35.63 \\
\hline 275 & 41.30 & 39.60 & 39.96 & 39.81 \\
\hline 300 & 45.50 & 43.80 & 44.13 & 44.06 \\
\hline 325 & 49.72 & 47.73 & $\frac{1}{28.29}$ & 48.27 \\
\hline 350 & 53.97 & 52.54 & 52.56 & 52.53 \\
\hline 375 & 58.24 & 56.54 & 56.96 & 56.95 \\
\hline 400 & 62.53 & 60.94 & 61.41 & 61.34 \\
\hline 425 & 66.86 & 65.55 & 65.89 & 65.79 \\
\hline 450 & 71.22 & 69.94 & 70.33 & 70.19 \\
\hline 475 & 75.61 & 74.54 & 74.75 & 74.73 \\
\hline 500 & 80.04 & 79.05 & 79.04 & 79.01 \\
\hline 525 & 84.51 & 83.39 & 83.77 & 83.52 \\
\hline 550 & 89.02 & 87.73 & 88.40 & 88.13 \\
\hline 575 & 93.58 & 92.11 & 92.64 & 92.59 \\
\hline 600 & 98.17 & 96.14 & 96.57 & 96.75 \\
\hline 625 & 102.82 & 100.48 & 101.01 & 101.16 \\
\hline 650 & 107.52 & 104.87 & 105.52 & 105.78 \\
\hline 675 & 112.27 & 109.77 & 110.21 & 110.41 \\
\hline 700 & 117.07 & $11 \div .12$ & 114.85 & 115.15 \\
\hline 725 & 121.93 & 118.96 & 119.57 & 119.83 \\
\hline 750 & 126.85 & 123.86 & 124.37 & 124.64 \\
\hline
\end{tabular}

* Equation fitted to mean thermal expansion coefficient data (4) is $I_{\mathrm{t}}{ }^{\circ} \mathrm{C}=\mathrm{I}_{0} 0^{\circ} \mathrm{C}\left(1+16.46 \times 10^{-6} \mathrm{t}-4.25 \times 10^{-9} \mathrm{t}^{2}+2.36 \times 10^{-12} \mathrm{t}^{3}\right)$. 
TABLE VII

Fraction Expansion of Pure Silver

$$
\left(\frac{L_{t}{ }^{\circ} \mathrm{C}-L_{25}{ }^{\circ} \mathrm{C}}{I_{25}{ }^{\circ} \mathrm{C}}\right)
$$

\begin{tabular}{|c|c|c|c|c|}
\hline \multirow{2}{*}{$\begin{array}{c}\text { Temperature } \\
\left({ }^{\circ} \mathrm{C}\right)\end{array}$} & \multirow{2}{*}{$\begin{array}{l}\text { Calculated from } \\
\text { Equation } \\
\times 10^{4}\end{array}$} & \multicolumn{3}{|c|}{$\begin{array}{l}\text { Calculated from Experimental } \\
\text { Measurements } \times 10^{4} \\
\text { (Average of } 5 \text { Determinations) }\end{array}$} \\
\hline & & L'Scale & I' Scale & $H^{\prime}$ Scale \\
\hline 25 & 0.00 & 0.00 & 0.00 & 0.00 \\
\hline 50 & 4.89 & 4.31 & 4.43 & 4.44 \\
\hline 75 & 9.80 & 8.81 & 8.73 & 8.82 \\
\hline 100 & 14.73 & 13.58 & 13.63 & 13.59 \\
\hline 125 & 19.68 & 18.56 & 18.65 & 18.59 \\
\hline 150 & 24.64 & 23.29 & 23.64 & 23.25 \\
\hline 175 & 29.66 & 28.30 & 28.72 & 28.52 \\
\hline 200 & 34.69 & 33.42 & 33.79 & 33.54 \\
\hline 225 & 39.75 & 38.40 & 38.65 & 38.67 \\
\hline 250 & 44.84 & 43.26 & 43.86 & 44.10 \\
\hline 275 & 49.97 & 48.65 & 49.11 & 49.02 \\
\hline 300 & 55.14 & 53.93 & 54.30 & 54.20 \\
\hline 325 & 60.35 & 59.15 & 59.78 & 59.51 \\
\hline 350 & 65.60 & 64.48 & 65.36 & 64.93 \\
\hline 375 & 70.89 & 70.01 & 70.71 & 70.20 \\
\hline 400 & 76.23 & 75.39 & 76.17 & 75.72 \\
\hline 425 & 81.62 & 80.93 & 81.72 & 81.11 \\
\hline 450 & 87.05 & 86.50 & 87.35 & 86.85 \\
\hline 475 & 92.54 & 91.98 & 92.92 & 92.36 \\
\hline 500 & 98.09 & 07.83 & 98.61 & 98.01 \\
\hline 525 & 103.70 & $10: .56$ & 104.39 & 103.81 \\
\hline 550 & 109.36 & 100.20 & 110.22 & 109.60 \\
\hline 575 & 115.09 & 115.23 & 116.26 & 115.58 \\
\hline 600 & 120.88 & 121.32 & 122.35 & 121.56 \\
\hline 625 & 126.74 & 127.47 & 128.55 & 127.69 \\
\hline 650 & 132.66 & 133.21 & 134.66 & 133.78 \\
\hline 675 & 138.60 & 139.81 & 140.92 & 139.91 \\
\hline 700 & 144.73 & 1.10 .20 & $1+7.24$ & 146.12 \\
\hline 725 & 150.87 & 153.08 & 153.92 & 152.48 \\
\hline 750 & 157.10 & 159.58 & 160.29 & 158.92 \\
\hline
\end{tabular}

* Equation reported by Esser and Eusterbrook ${ }^{(5)}$ for pure silver is $L_{t}{ }^{\circ} \mathrm{C}=I_{0}{ }^{\circ} \mathrm{C}\left(1+19.4^{9} \times 10^{-6} \mathrm{t}+1.04 \times 10^{-9} \mathrm{t}^{2}+2.38 \times 10^{-12} \mathrm{t}^{3}\right)$. 
Figure 1. Thermal Lxpansion liecorder.

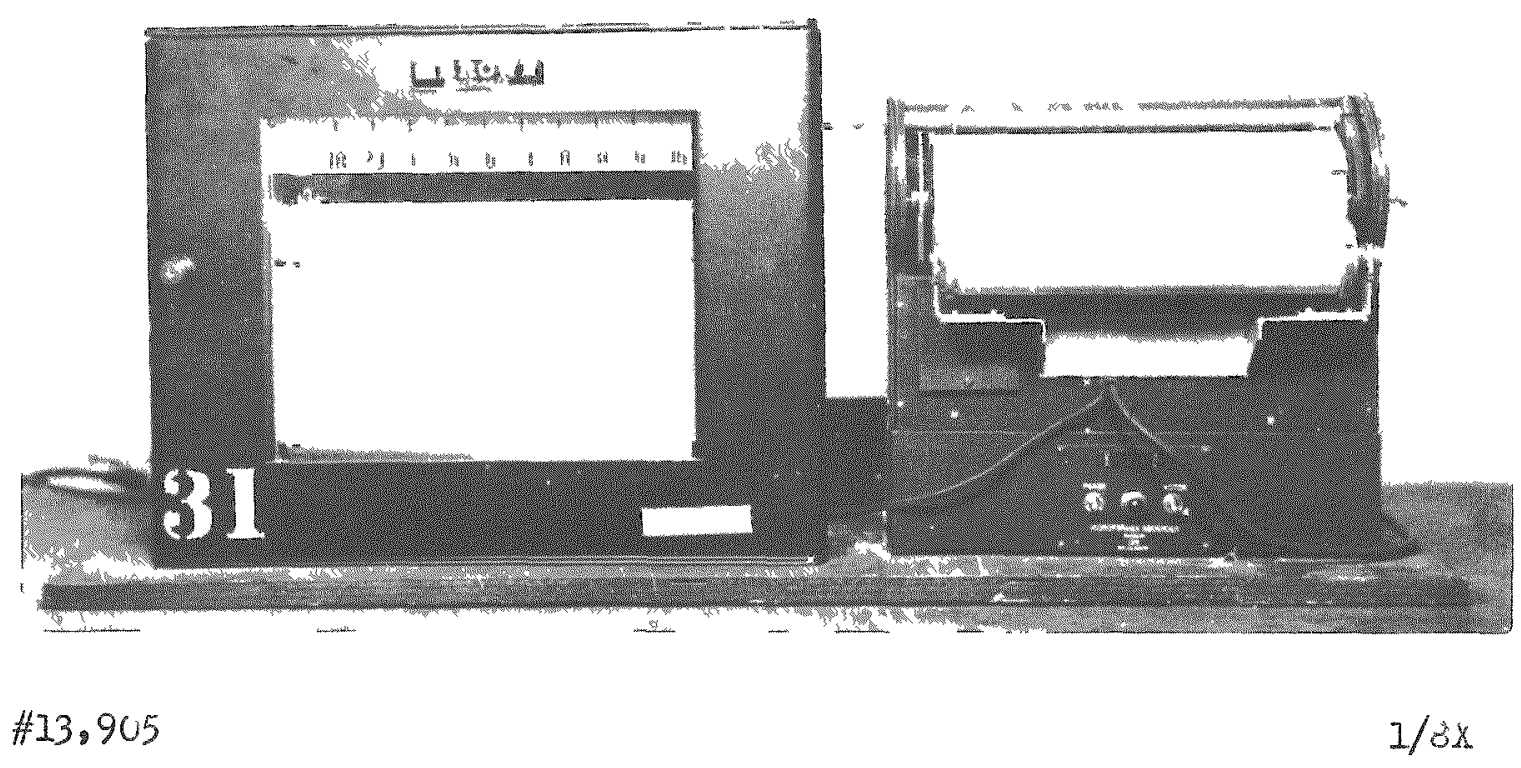


FIGURE 2

DILATOMETER QUARTZ ASSEMBLY

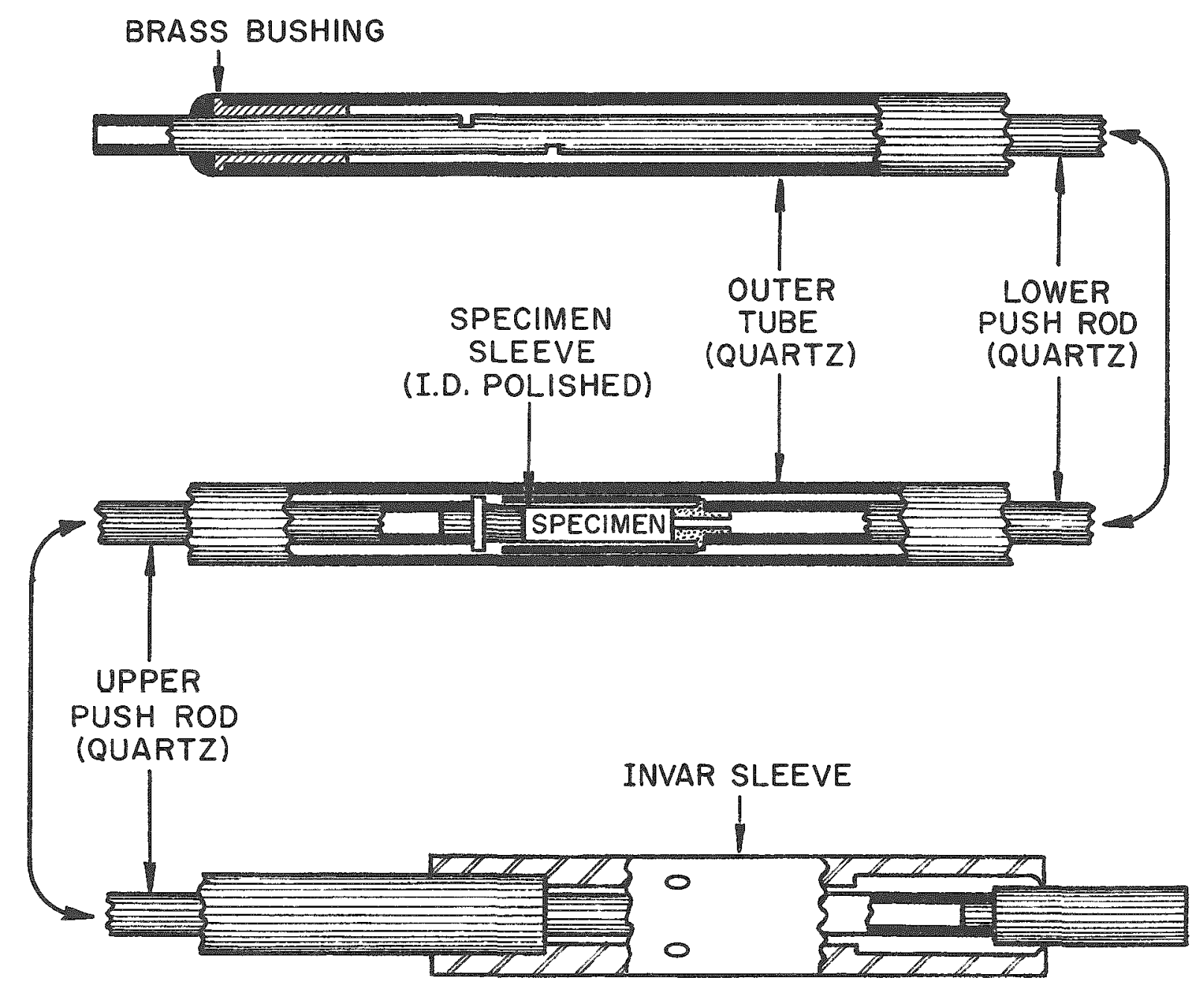

PLUGS FUSED TO UPPER AND LOWER PUSH RODS ARE GROUND AND POLISHED 
Figure 3. Invar Vlamp and Lever Arm between Upper Push Rod and Linear Variable Difrerential Tionsformer core.

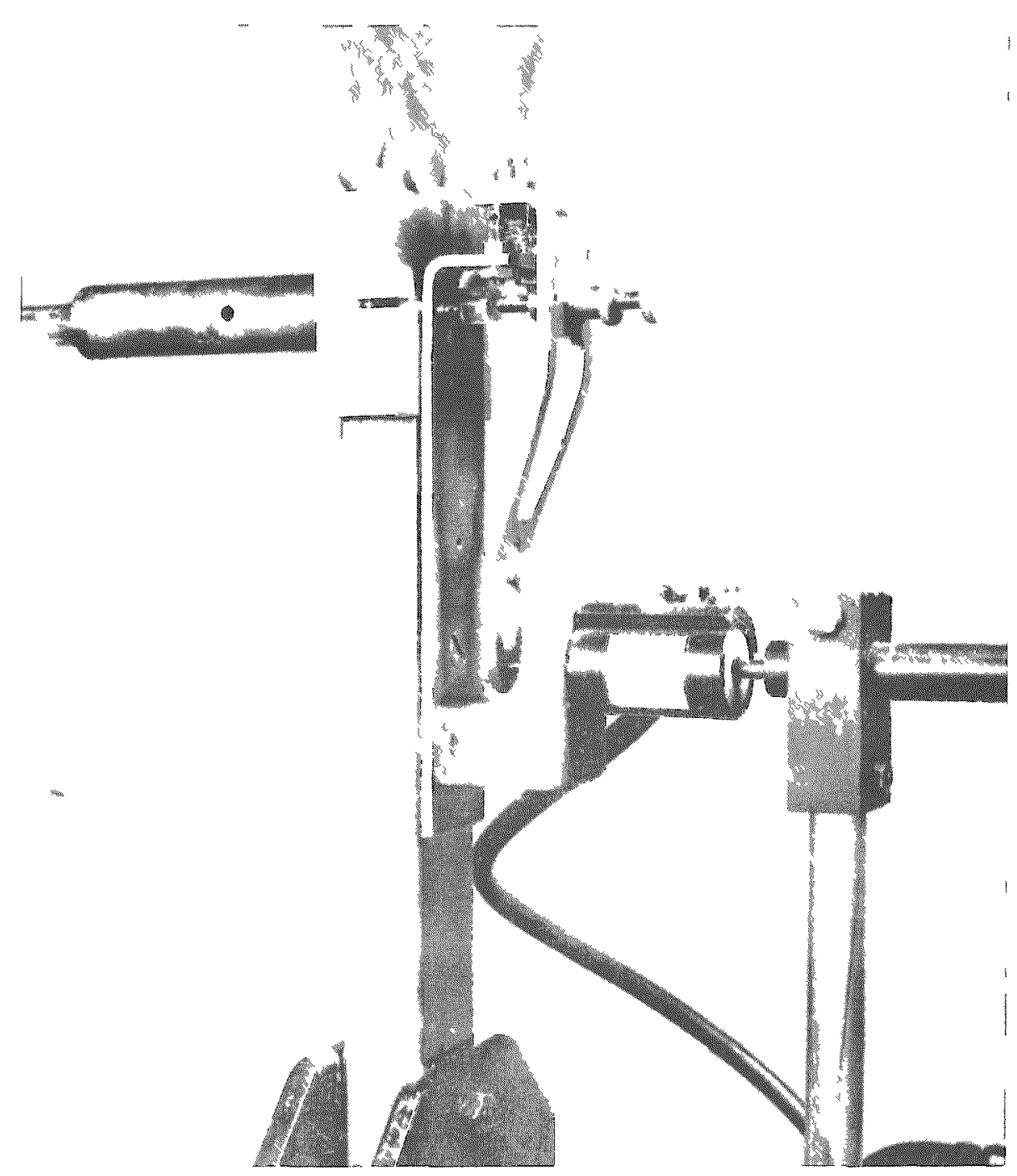

$\$ 13,402$ 
Figure 4. Dilatometer Assembly.

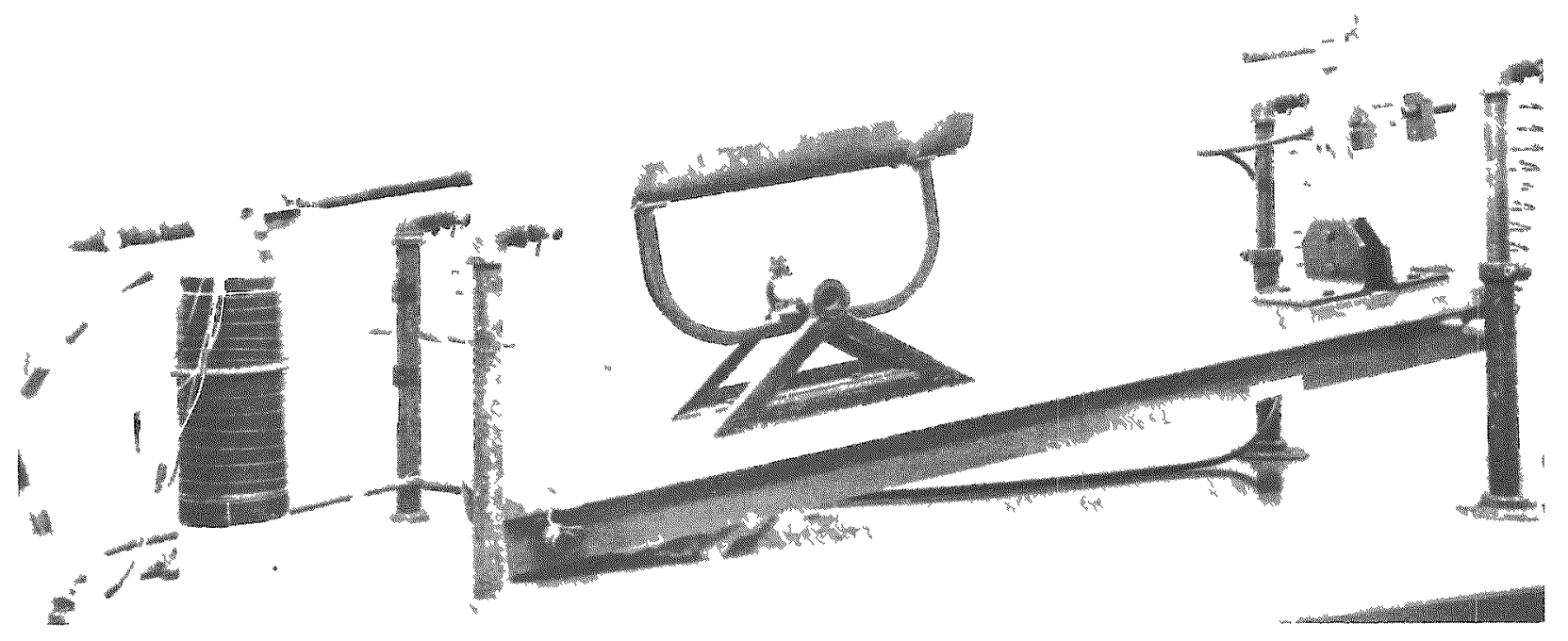

$\# 25,190$ 
FIGURE 5

LOW MASS FURNACE FOR FAST HEATING AND COOLING RATES

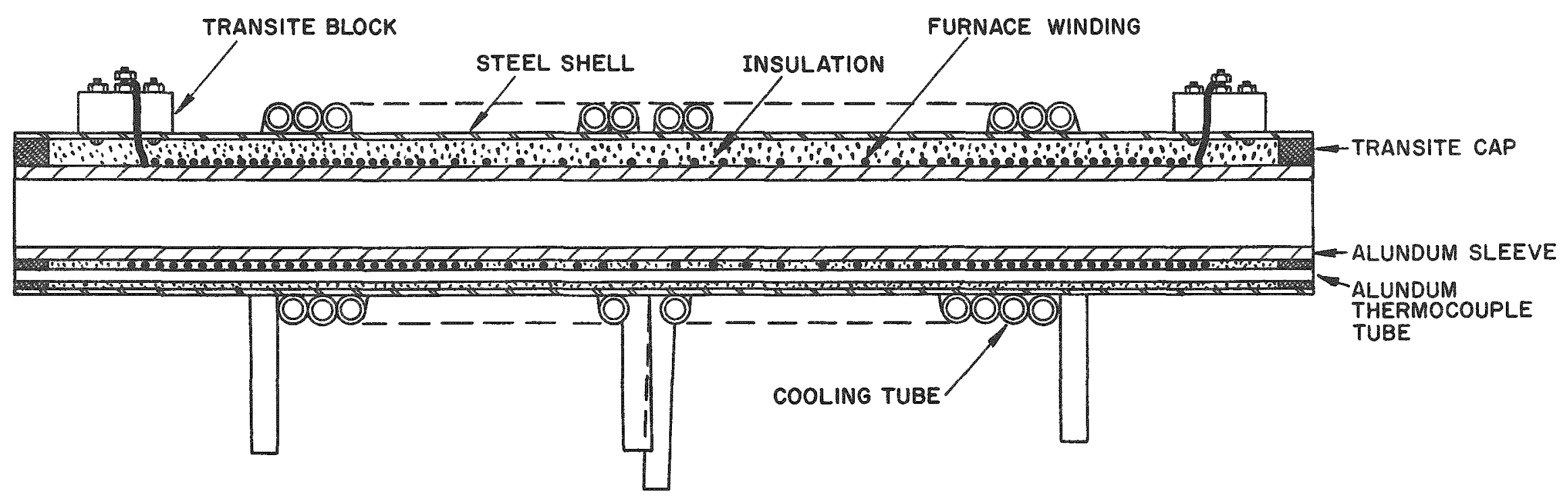


FIGURE 6

TEMPERATURE GRADIENTS OF FAST HEATING AND COOLING RATE FURNACE

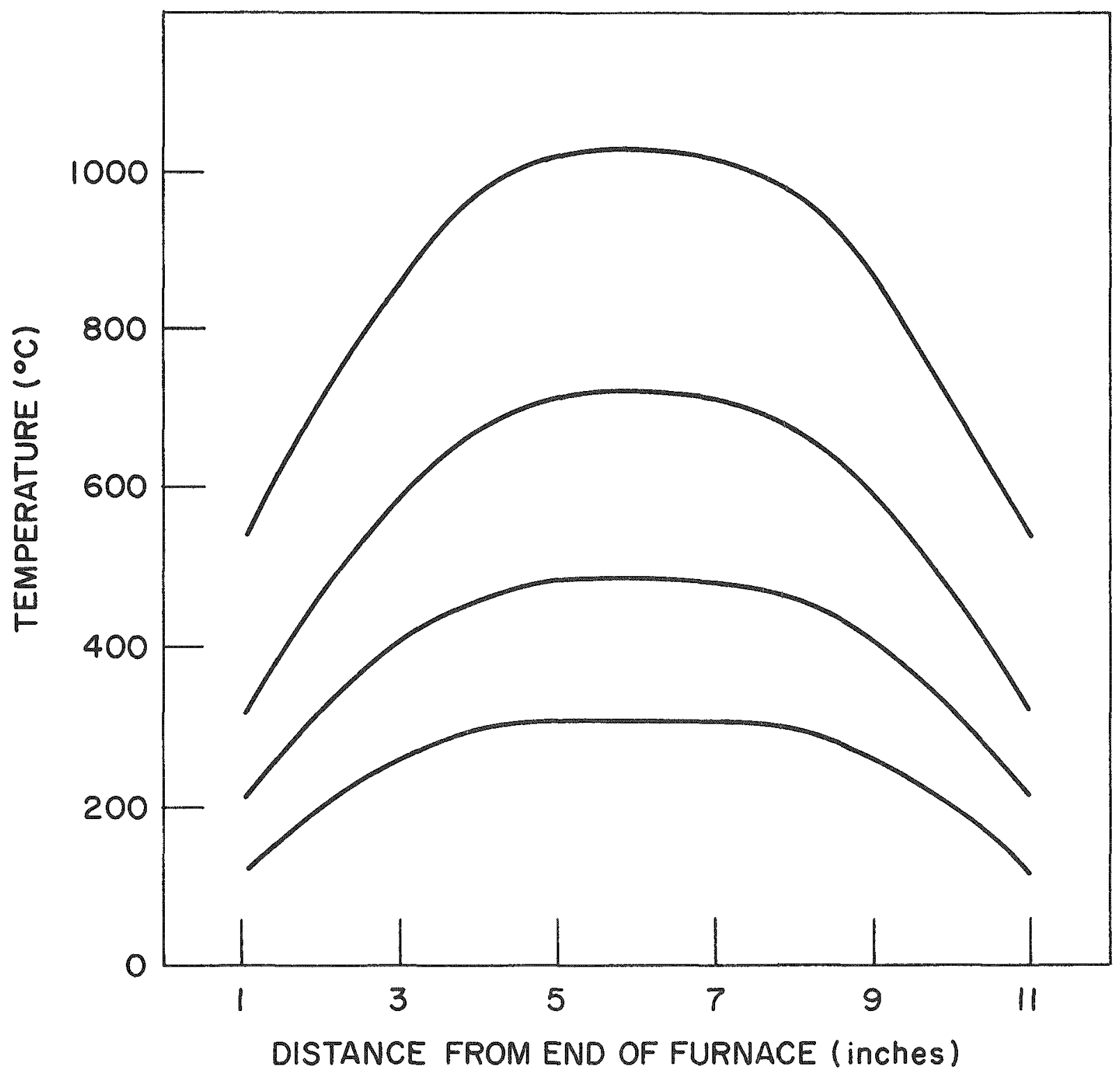


FIGURE 7

SLOWER HEATING AND COOLING RATE FURNACE

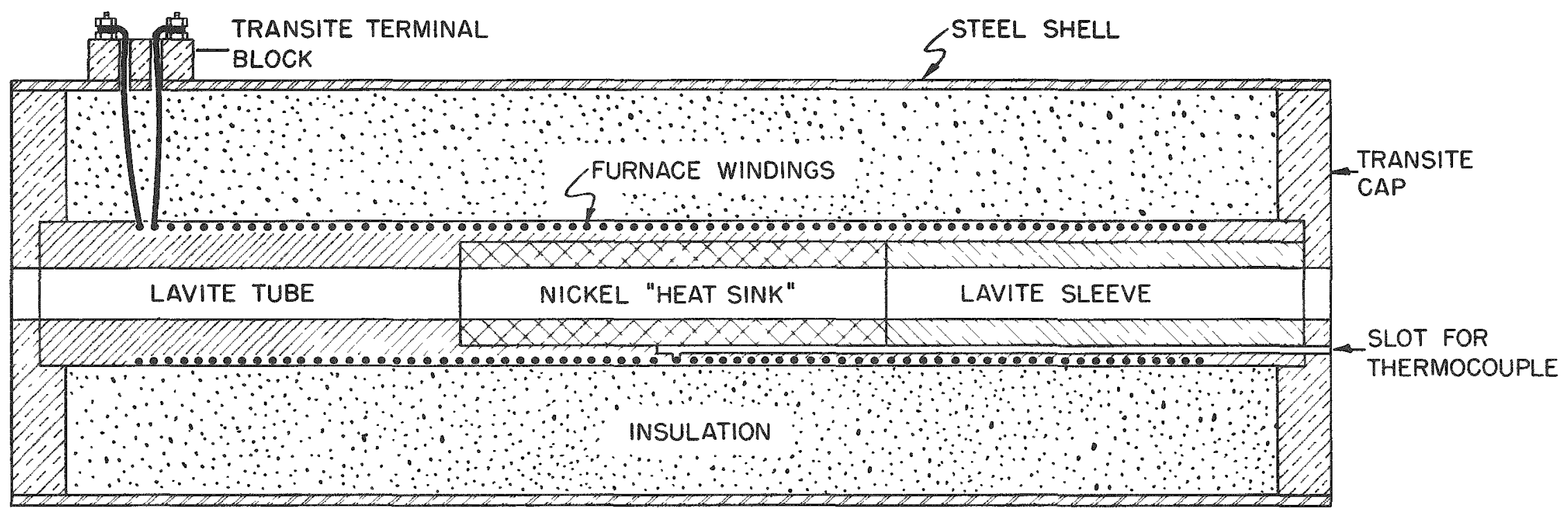


Figure 8. Recorder and Control Instrument Console of the Dilatometer.

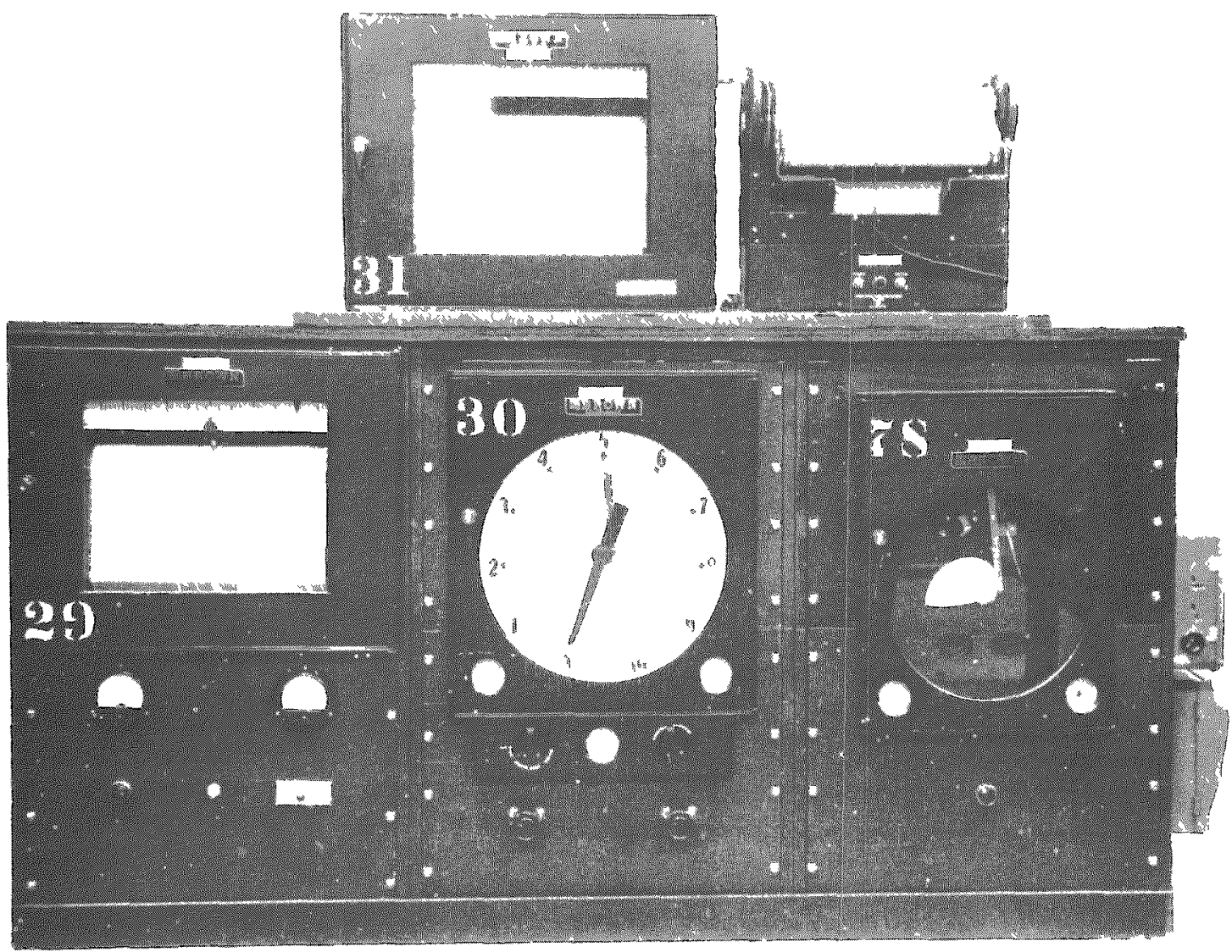

125,142 
Figure 9. Over-all View of Quartz Difierential Dilatometer and Associated Equipment.

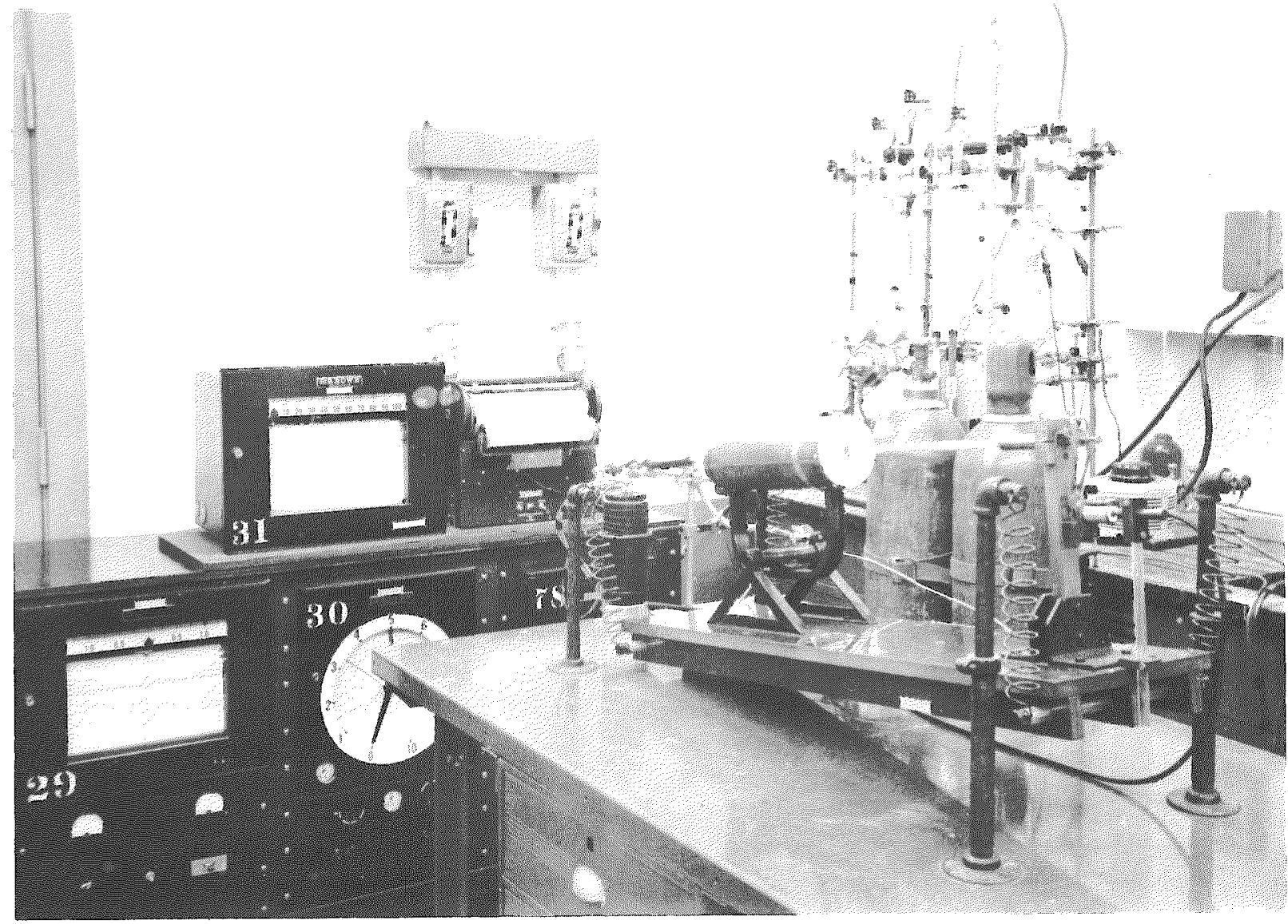

\#25,191 
FIGURE 10

SCHEMATIC SKETCH OF MECHANICAL LINKAGES IN THE BALDWIN RECORDER

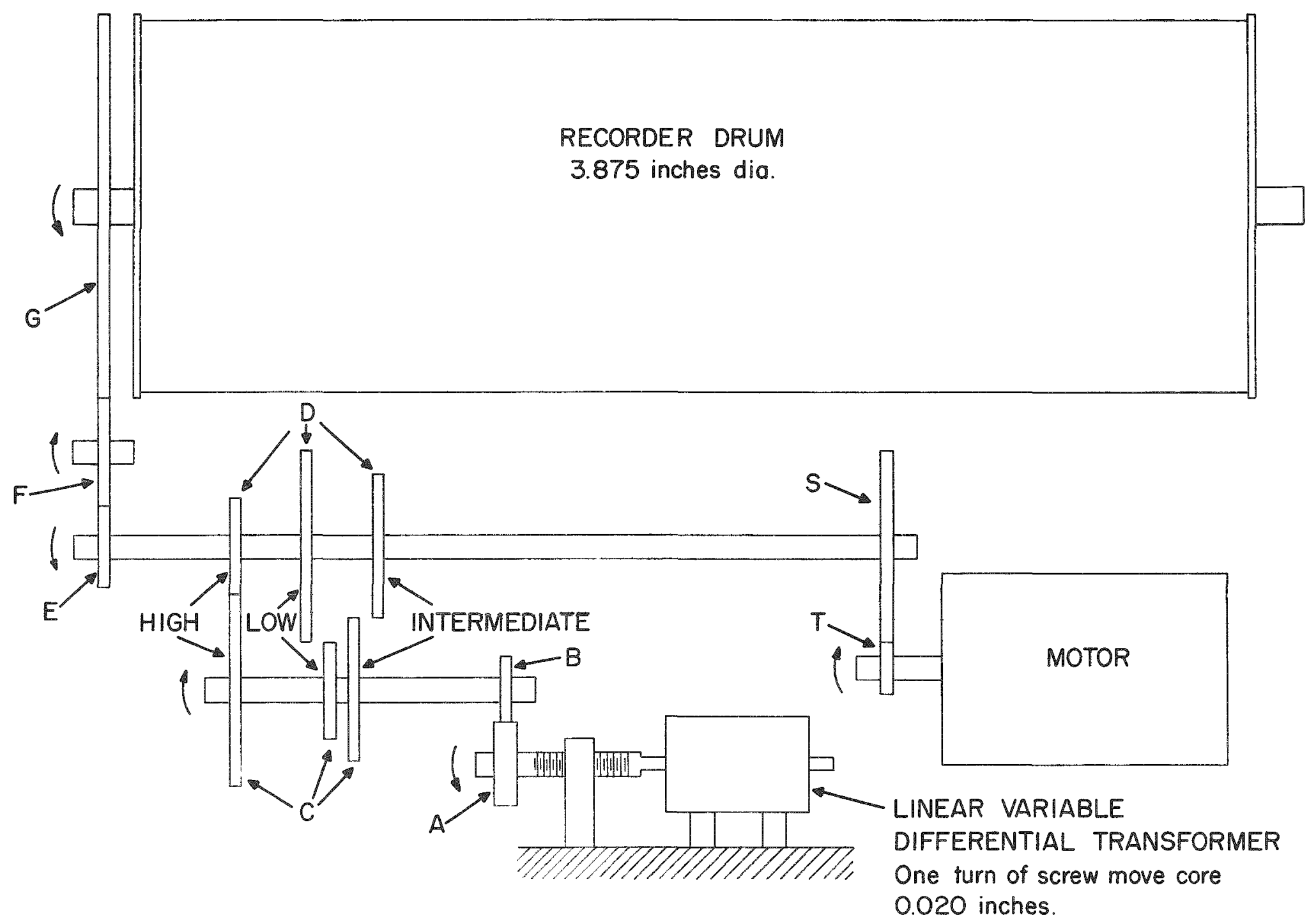


FIGURE II

SCHEMATIC REPRESENTATION OF CORRECTION APPLIED FOR EXPANSION OF QUARTZ ASSEMBLY COMPONENTS

a.

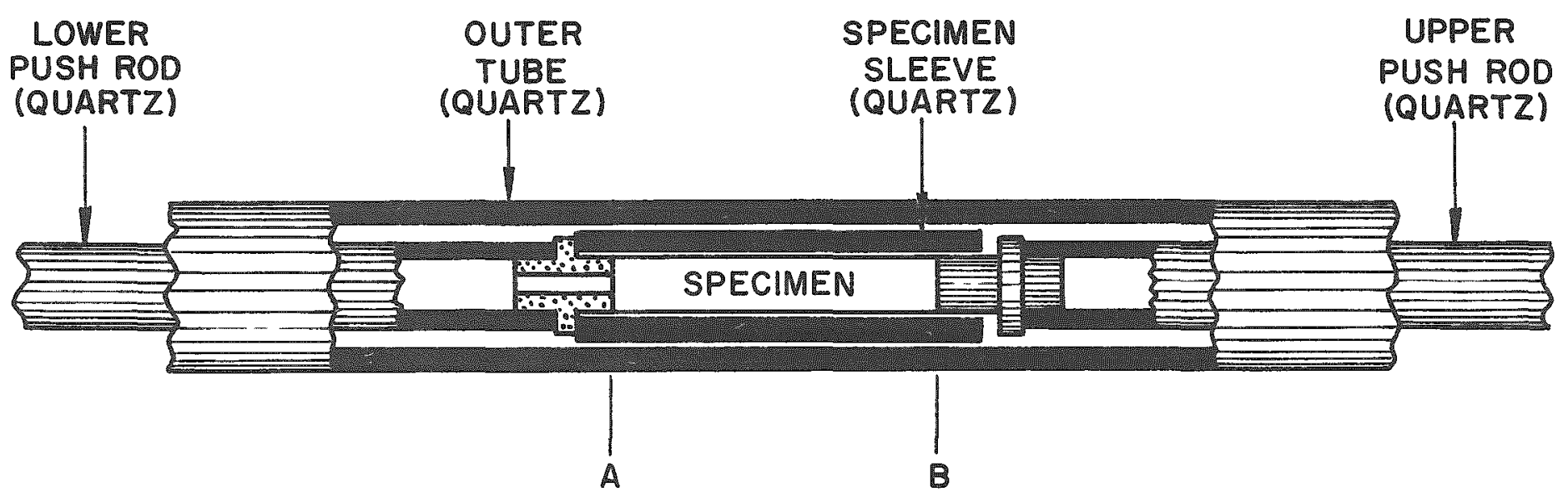

b.

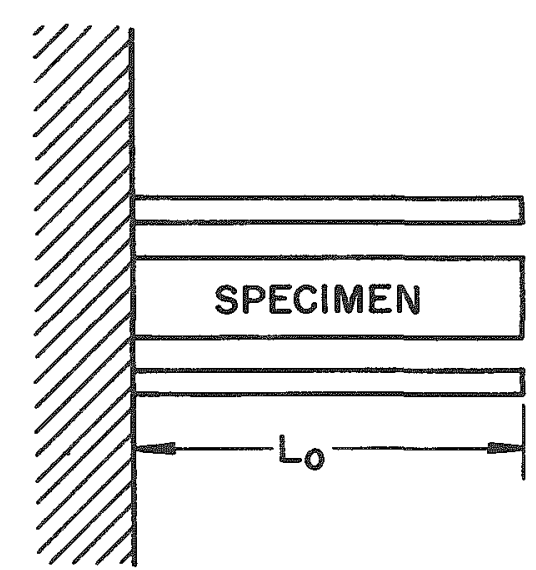

A c.

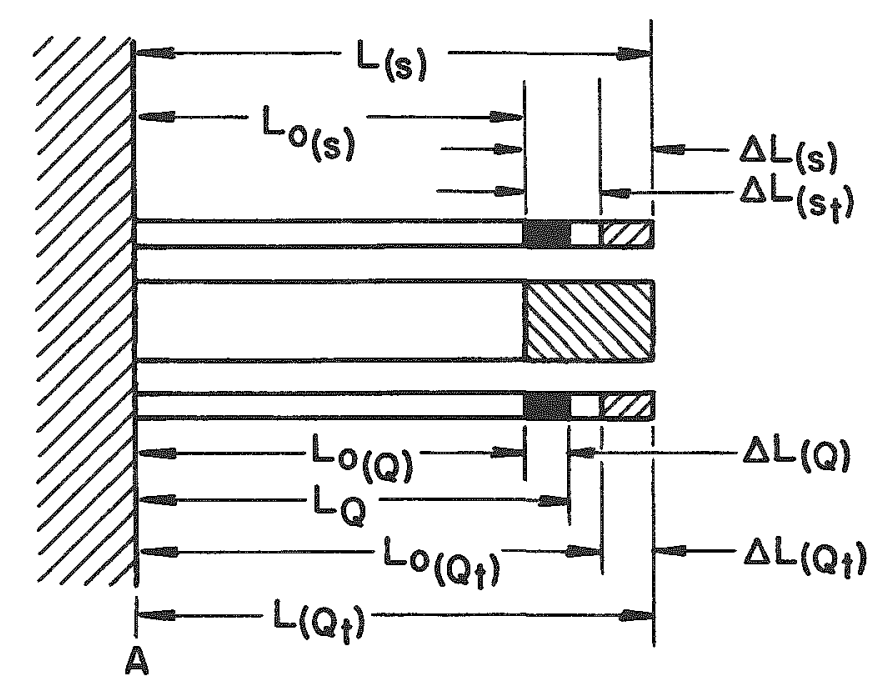


FIGURE 12

FRACTION EXPANSIONS OF SPECIMENS DQ AND PURE SILVER

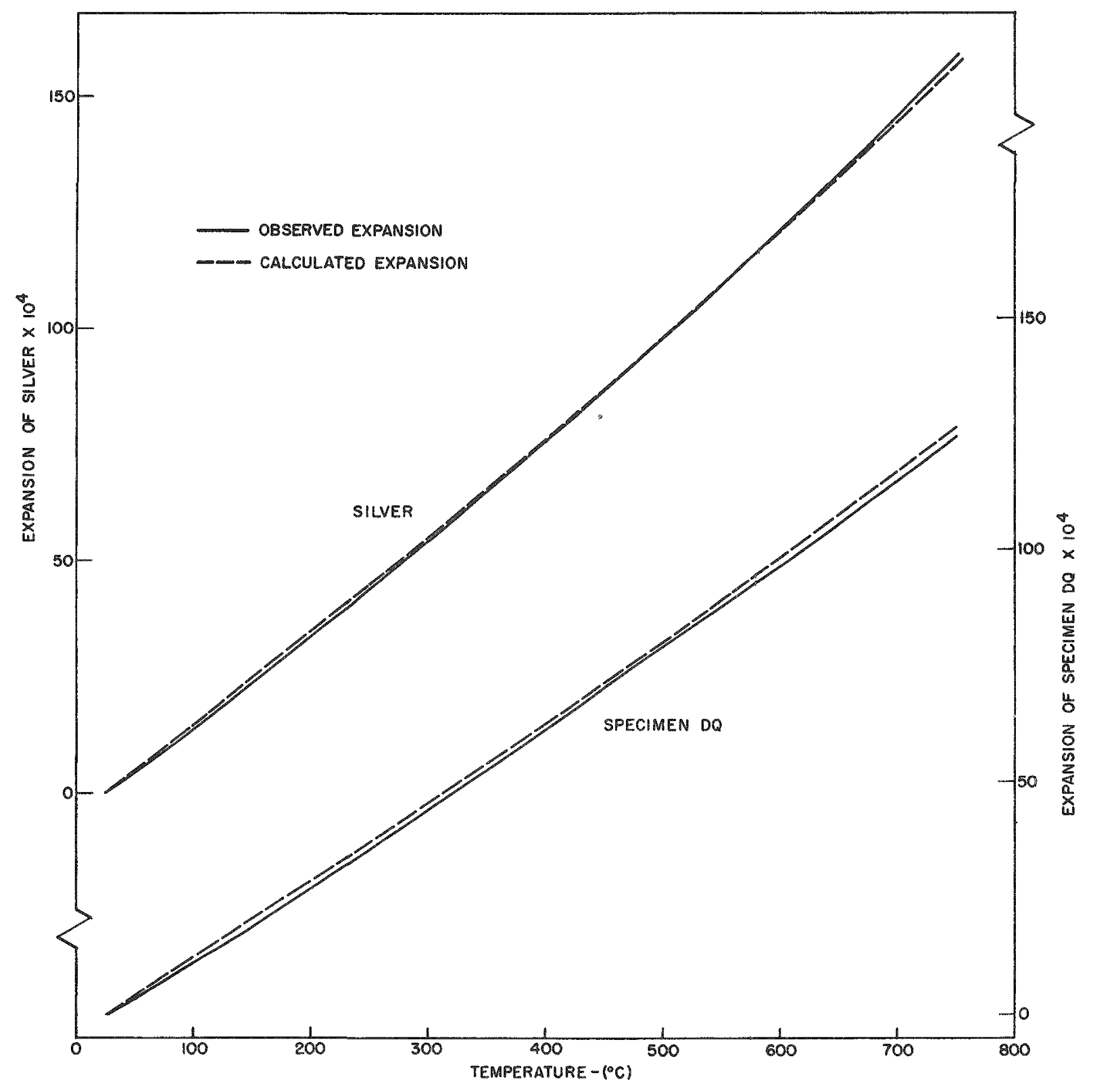


FIGURE 13

SCHEMATIC DIAGRAM OF AIR SYSTEM FOR RECORDING

QUARTZ DIFFERENTIAL DILATOMETER

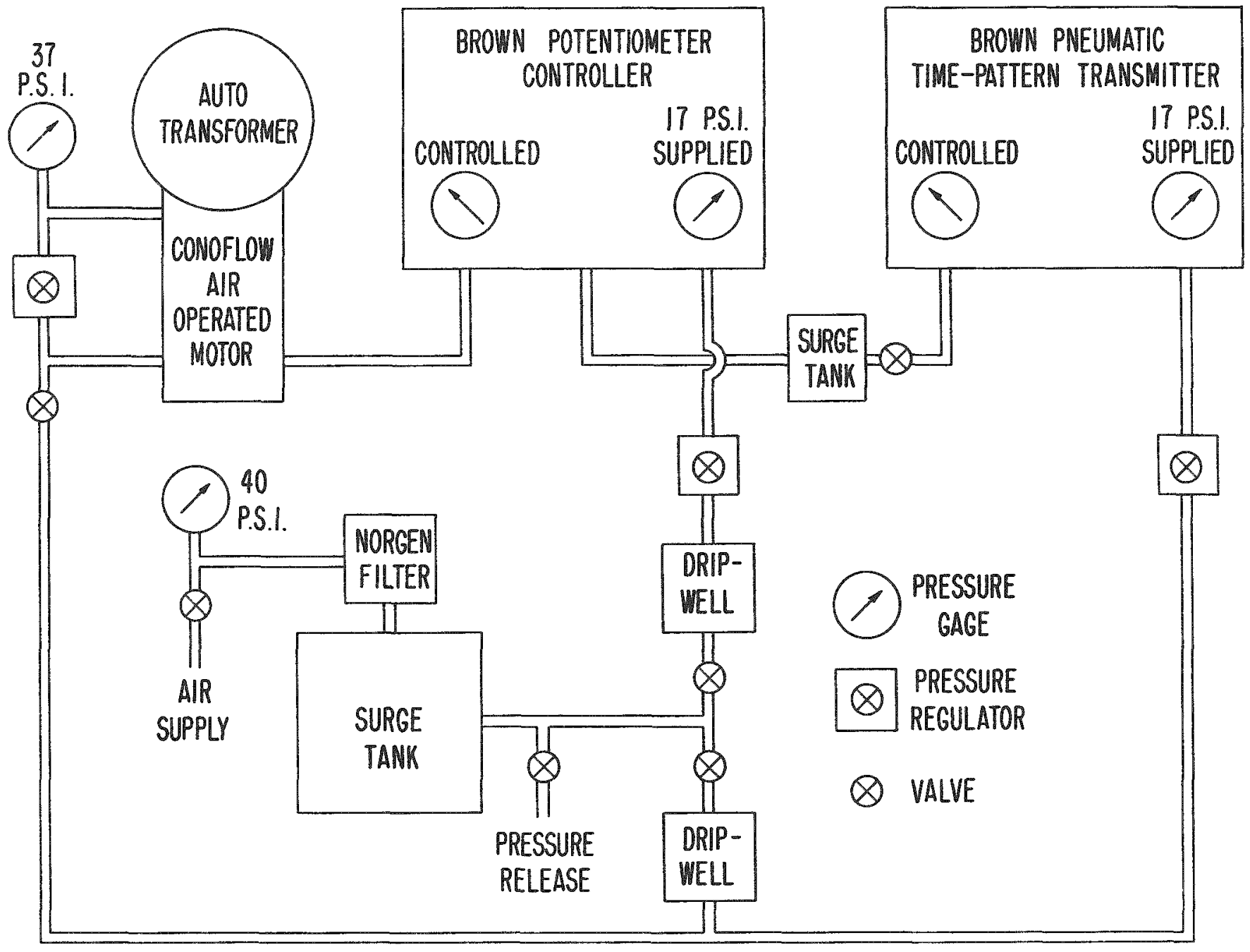


FIGURE 14

SCHEMATIC WIRING DIAGRAM FOR GAS PURIFICATION TRAIN OF RECORDING QUARTZ DIFFERENTIAL DILATOMETER

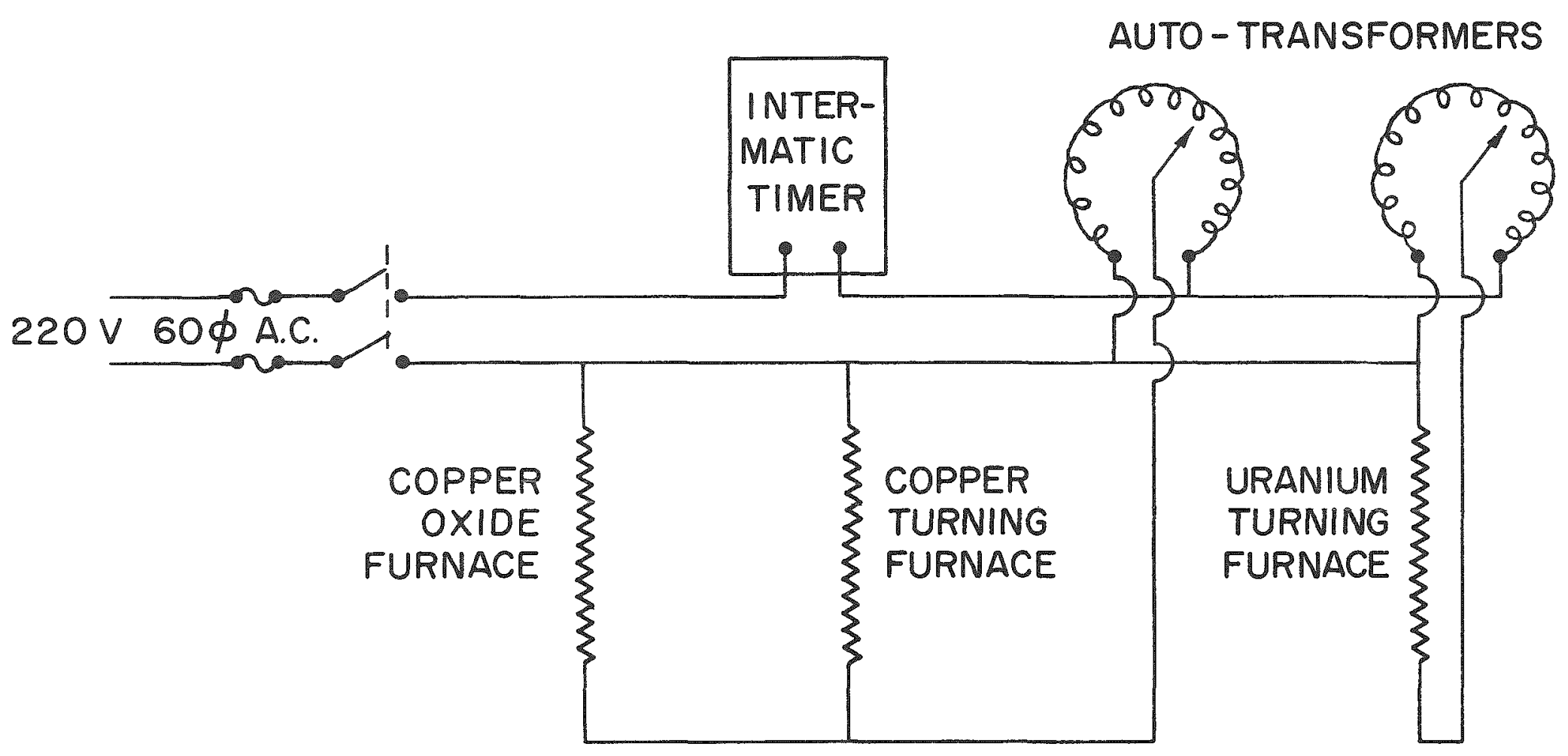


FIGURE 15

SCHEMATIC POWER WIRING DIAGRAM FOR RECORDER AND CONTROL INSTRUMENTS OF RECORDING QUARTZ DIFFERENTIAL DILATOMETER

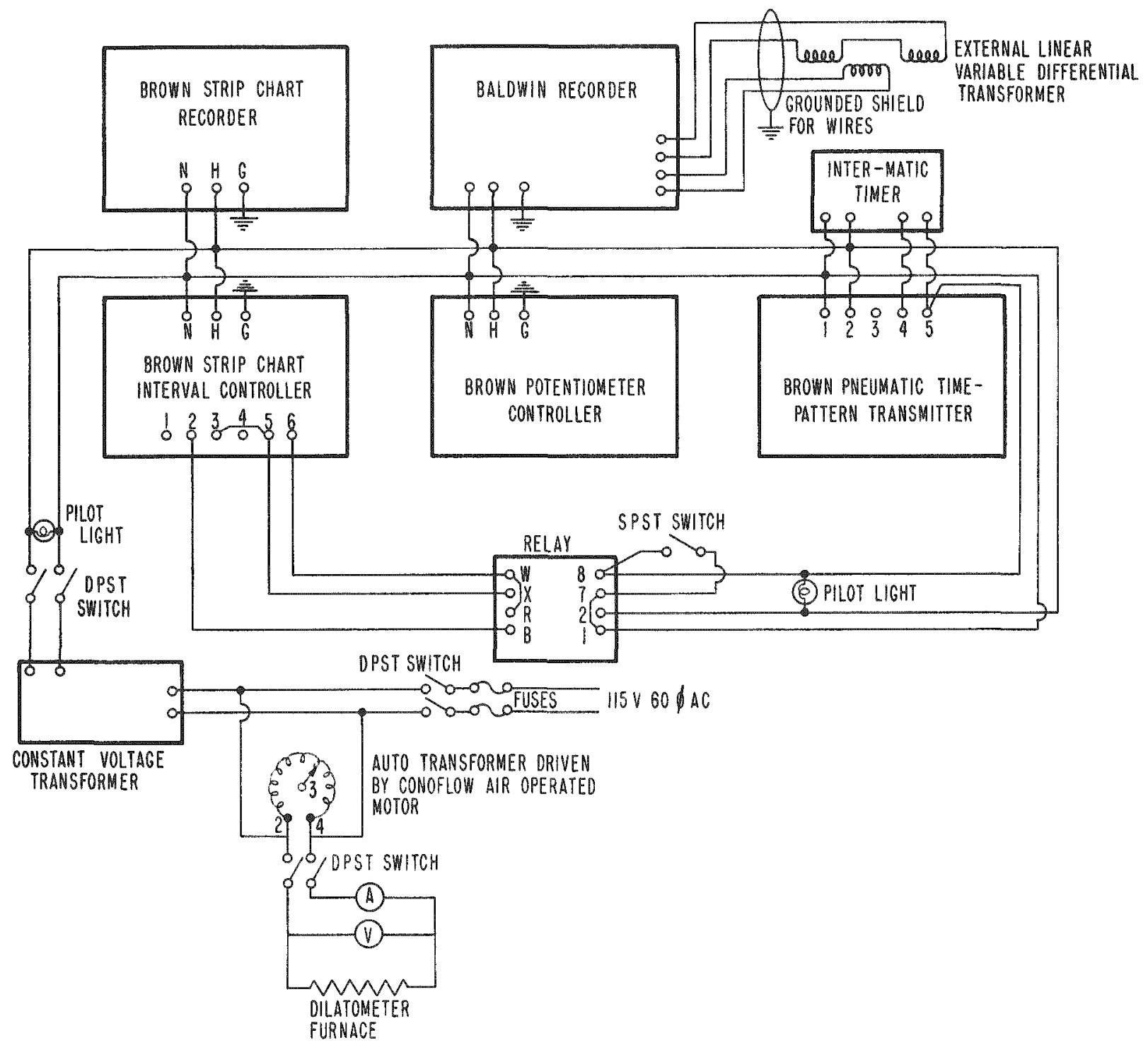


FIGURE 16

SCHEMATIC THERMOCOUPLE WIRING DIAGRAM FOR RECORDER AND CONTROL INSTRUMENTS OF RECORDING QUARTZ DIFFERENTIAL DILATOMETER

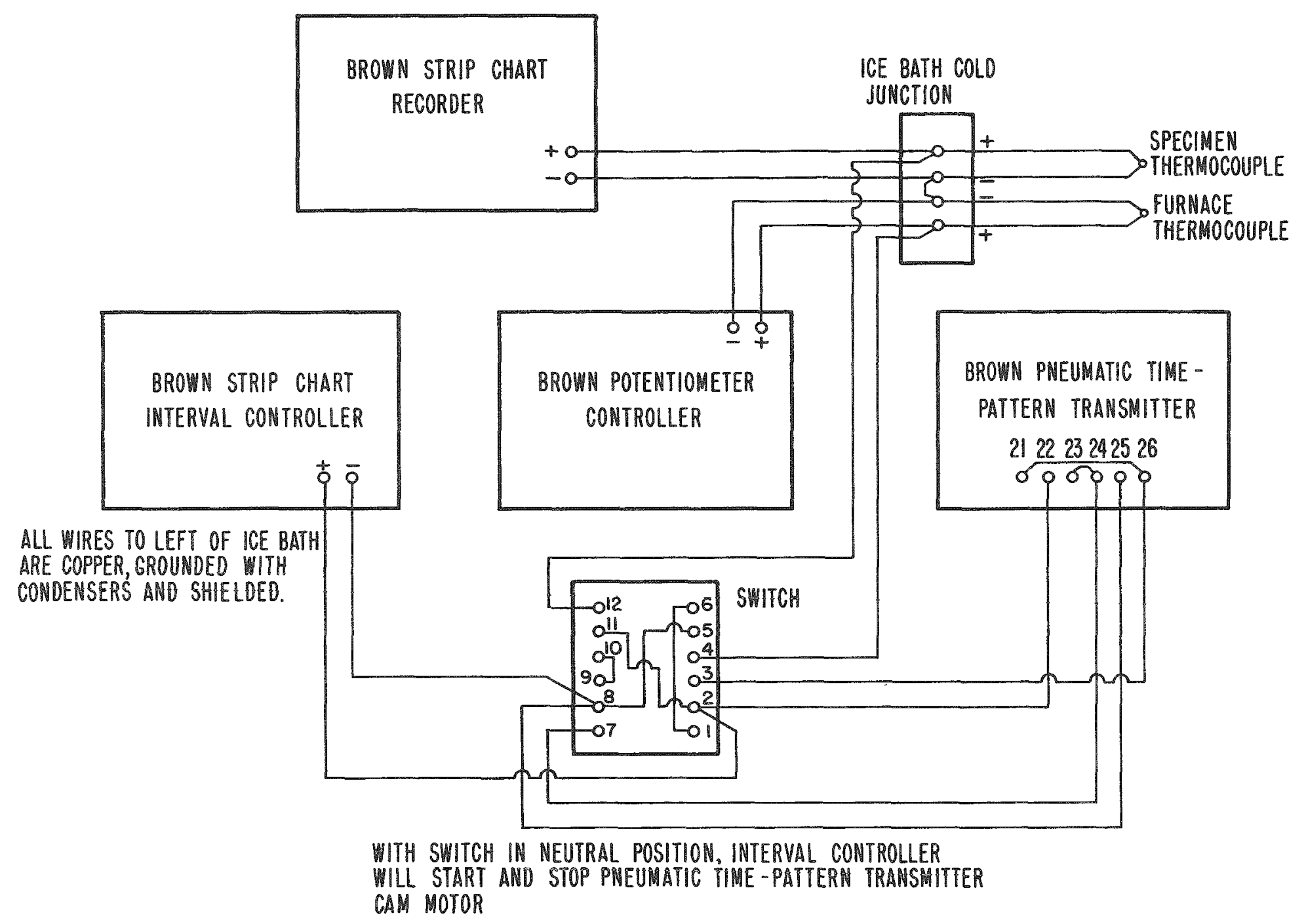


FIGURE 17

THERMAL EXPANSION CURVES FOR $300^{\circ} \mathrm{C}$ ROLLED AND 2 HOUR $575^{\circ} \mathrm{C}$ ANNEALED URANIUM ROD SAMPLE TESTED IN A DIRECTION PARALLEL TO THE ROLLING DIRECTION. SAMPLE WAS CYCLED BETWEEN $30^{\circ}$ AND $630^{\circ} \mathrm{C}$.

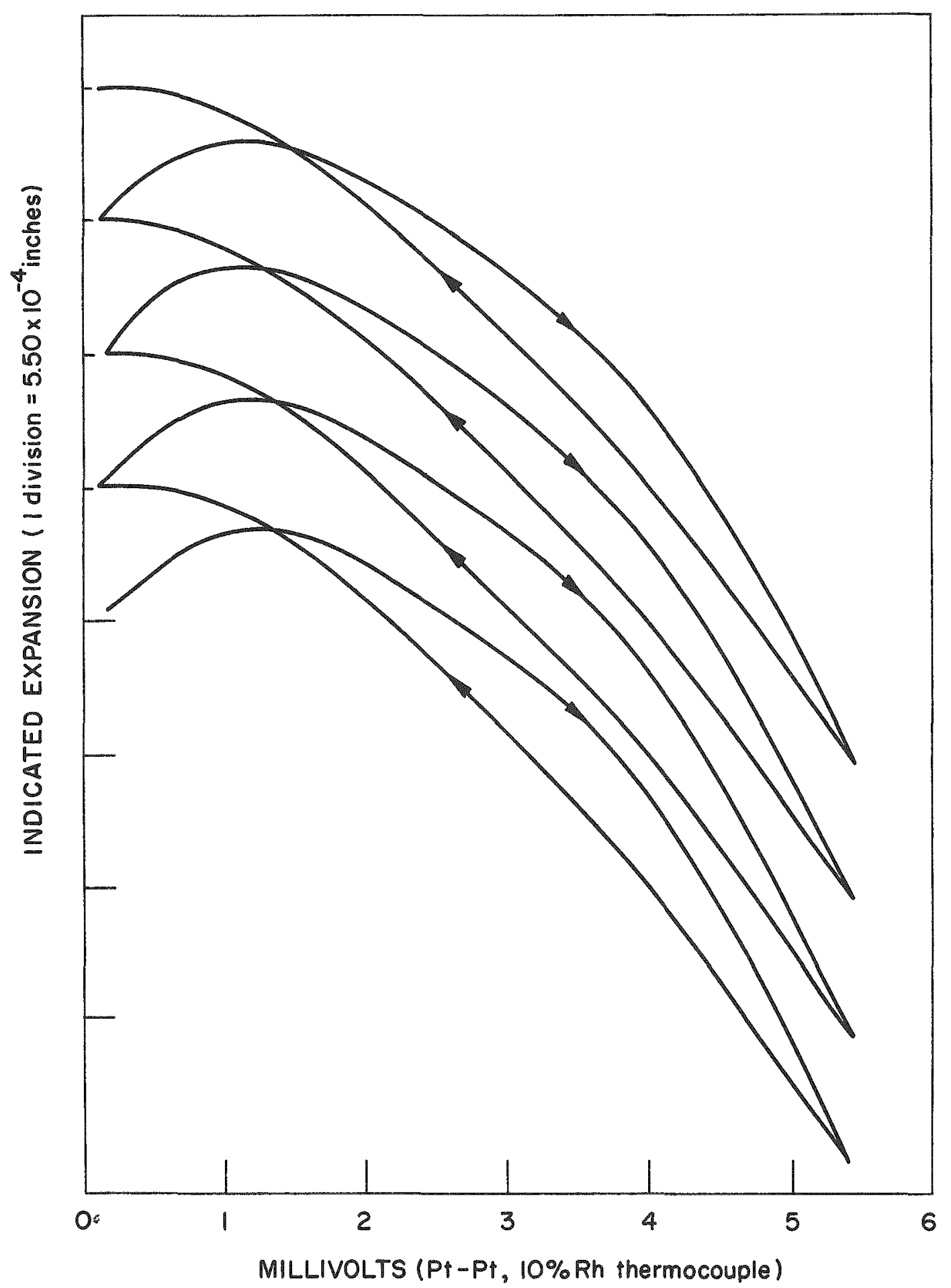


FIGURE 18

THERMAL EXPANSION CURVES FOR $300^{\circ} \mathrm{C}$ ROLLED AND $575^{\circ} \mathrm{C}$ ANNEALED URANIUM ROD SAMPLES TESTED PARALLEL TO THE ROLLING DIRECTION.

a. NORMAL BEHAVIOR OF CONTRACTION UPON COOLING IN THE ALPHA PHASE.

b. ABNORMAL EXPANSION UPON COOLING IN THE ALPHA PHASE.

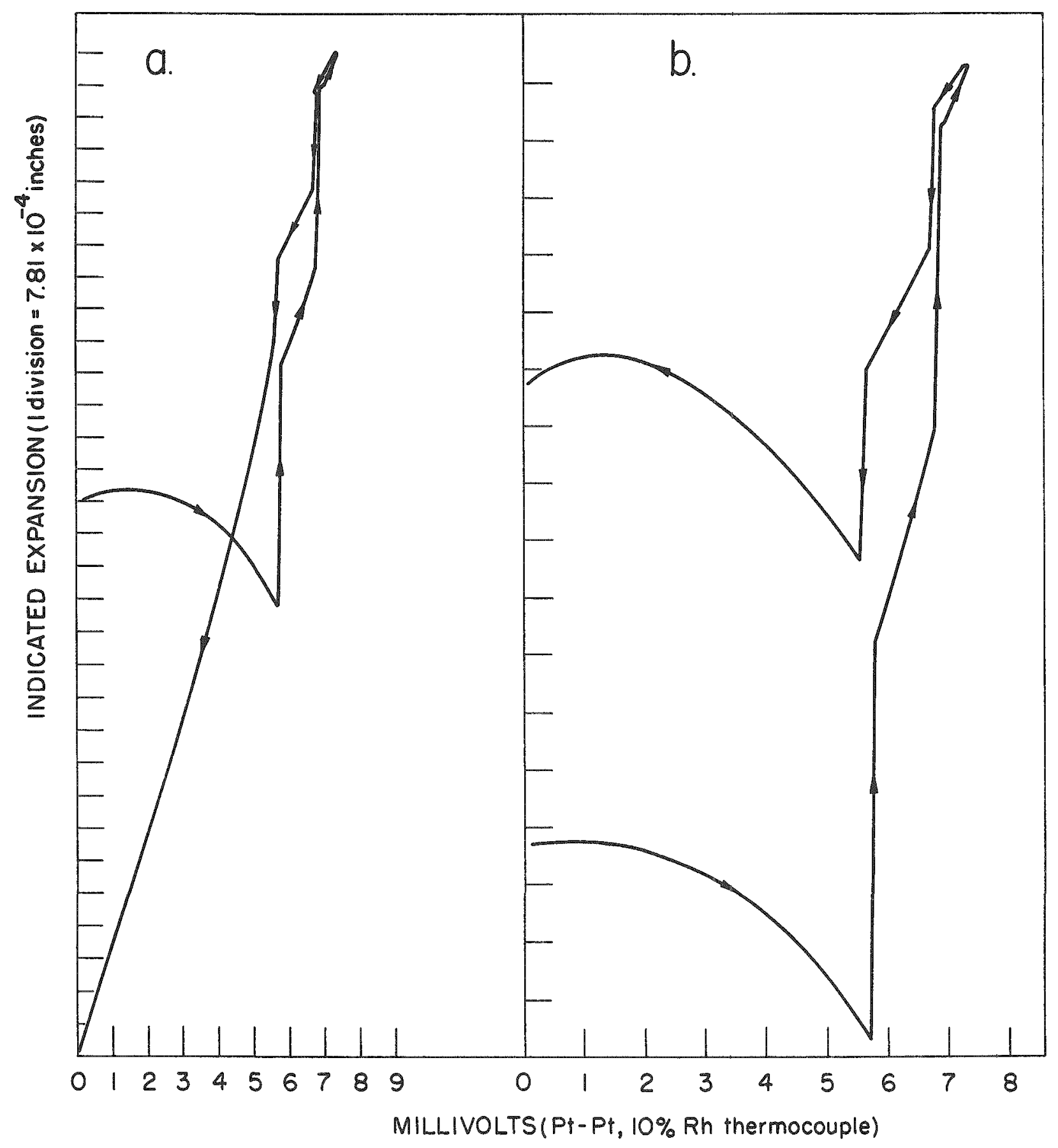


FIGURE 19

EXPANSION OF AN ALPHA-URANIUM SINGLE CRYSTAL IN A DIRECTION NEAR THE[OIO]

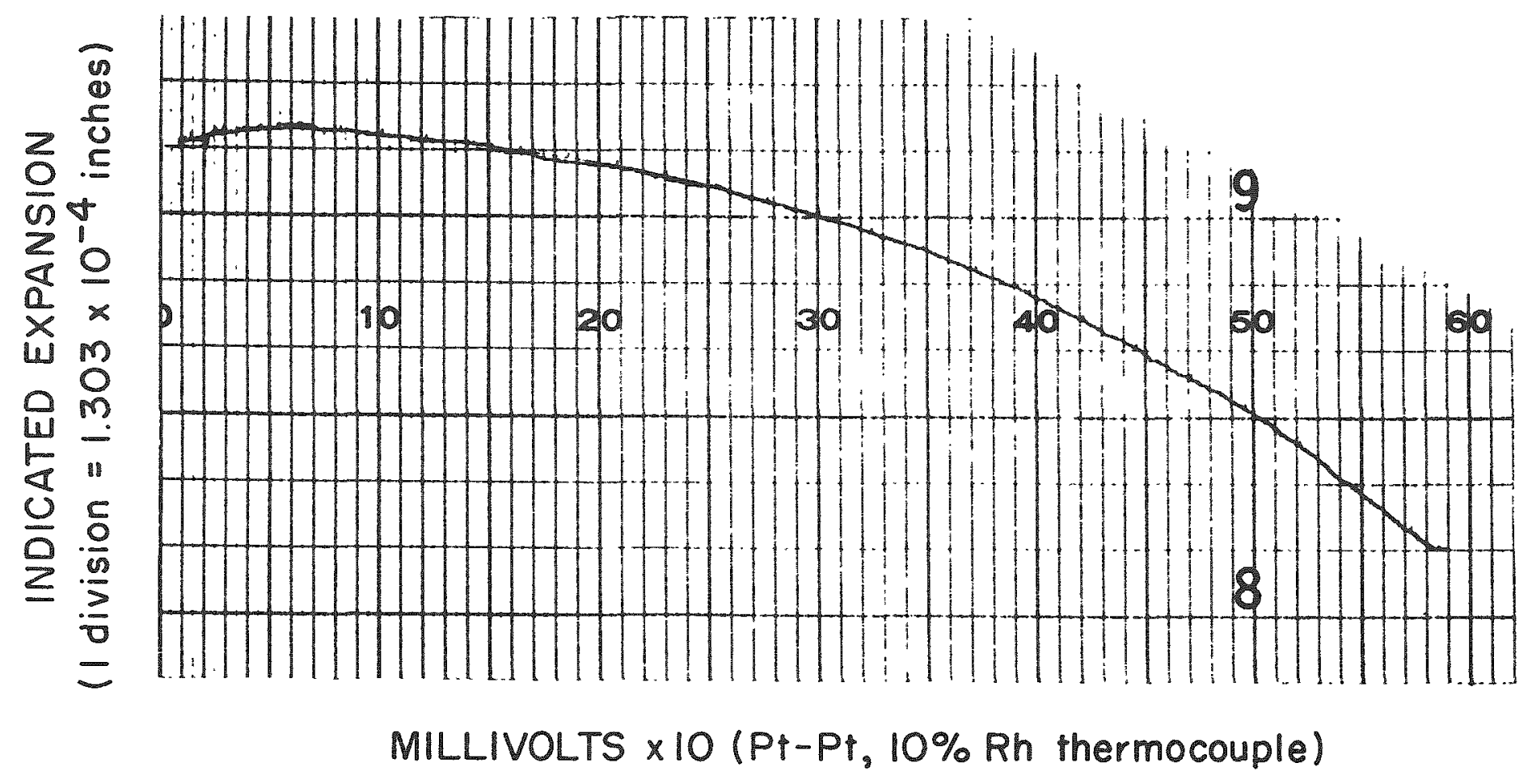

